\title{
Kinematics of Inner Shelf Motions during the Summer Stratified Season off New Jersey*
}

\author{
Andreas Münchow and Robert J. Chant \\ Institute of Marine and Coastal Sciences, Rutgers University, New Brunswick, New Jersey
}

(Manuscript received 14 August 1998, in final form 6 January 1999)

\begin{abstract}
Subinertial currents on a wide $(\sim 100 \mathrm{~km})$, shallow $(\sim 20 \mathrm{~m})$, but nevertheless vertically stratified shelf off the Atlantic seaboard of the United States are investigated at spatial scales of about $20 \mathrm{~km}$ in the alongshore and $10 \mathrm{~km}$ in the across-shore direction. During the summer of 1996 the inner shelf off New Jersey was stratified due to both temperature and salinity that varied vertically by more than $12^{\circ} \mathrm{C}$ and $4 \mathrm{psu}$, respectively. Upwelling favorable winds and an intermittent buoyancy-driven Hudson coastal current impact this stratification inshore of the $15-\mathrm{m}$ isobath. Waters offshore were always stratified except during the passage of Tropical Storm Bertha. Mean currents are weak because wind-forced upwelling and buoyancy-forced downwelling events occurred about evenly during the observational study period. At monthly to daily timescales currents always veered counterclockwise with depth in a bottom Ekman-layer sense by more than $30^{\circ}$ inshore and $50^{\circ}$ offshore. Complex empirical orthogonal function (CEOF) analyses revealed that these veering angles are contained in the first mode that explains $80 \%-85 \%$ of the total variance at individual locations. It also explains $72 \%$ of the variance of 44 current time series of an across-shore section. The veering constitutes a robust feature that cannot be rationalized by Ekman dynamics in shallow water alone. The authors hypothesize that the veering represents a frictional response common to both upwelling and downwelling events. The CEOF analysis does not separate wind from buoyancy forcing. The two forcing mechanisms thus appear to be dynamically coupled. Nevertheless, the first two CEOFs suggest distinctly different circulation regimes: For positive and negative temporal amplitudes mode 1 represents a wind-forced upwelling and a buoyancy-forced downwelling circulation while mode 2 represents the lateral shear of the flow field. Synoptic maps of surface currents from ocean surface current radar reveal realizations of these event types.
\end{abstract}

\section{Introduction}

Oceanographers have invoked the influence of the earth's rotation to explain ocean currents ever since Fridtjof Nansen noticed during his 1893-1896 Arctic expedition that his icebound ship, the Fram, drifted at an angle to the right of the wind. Ekman (1905) provided elegant solutions that qualitatively explained Nansen's observation in the last century and many more since. Successful quantitative verifications of the predicted Ekman spiral and associated mass flux, however, was accomplished only recently (Chereskin 1995). Ekman (1906) expanded the theory to include pressure gradients in the presence of a coast. Thorade (1909) and McEwen (1912) are cited by Sverdrup (1938) as the

\footnotetext{
* Institute of Marine and Coastal Sciences Contribution Number 98-28.

Corresponding author address: Dr. Andreas Münchow, Institute of Marine and Coastal Studies, Rutgers University, 71 Dudley Rd., New Brunswick, NJ 08901-8521.

E-mail: andreas@ahab.rutgers.edu
}

first to apply "Ekman dynamics" to the seasonal upwelling off California. More recently, Lentz (1992) quantified surface Ekman theory for coastal upwelling off Oregon, California, Peru, and northwest Africa. The systematic study of wind-forced coastal upwelling thus has a long history.

The first moored current meter observations of coastal upwelling were reported by Collins et al. (1968) and Blanton (1975) off Oregon and in Lake Ontario, respectively. More recent studies generally focused on narrow, steeply sloping shelves such as off Oregon, California, northwest Africa, and Peru where the water is deep enough to facilitate distinct surface and bottom Ekman layers. Examples of such comprehensive experiments are the Coastal Upwelling Ecosystems Analysis Experiment (Smith 1981), the Coastal Ocean Dynamics Experiment (Winant et al. 1987), and the Coastal Transition Zone Experiment (Brink and Cowles 1991). Motivated by these experiments, Lentz (1992) and Lentz and Trowbridge (1991) describe and analyze distinct surface and bottom boundary layer dynamics in coastal upwelling regions. Nevertheless, little is known on what happens if the water depth approaches the Ekman layer depth and surface and bottom Ekman layers interact. 
The details of this interaction impact across-shelf fluxes, which according to Csanady (1972) and Lentz (1995a) take place in a distinct inshore region that they termed the "coastal boundary layer" or the "inner shelf."

Csanady (1997) and Lentz (1995b) review the observational and theoretical literature on continental shelf processes through 1994. Both stress the importance of across-shelf exchange in the coastal zone. We refer to these reviews for background of the dynamics that generally affect shelf circulation and here briefly introduce only those studies that bear directly on the inner shelf. Csanady (1978) analytically models the steady barotropic circulation on the inner continental shelf in response to a wind stress that varies along a straight coast. The situation is dynamically similar to a more realistic situation of a uniform wind stress with a coastline that changes its orientation. The solution of the resulting vorticity balance revealed a coastal zone distinct from an offshore region. The main difference between these regions is that the momentum imparted by the wind stress is balanced by bottom friction inshore while it is balanced by the Coriolis force offshore. Allen et al. (1995) and Federuik and Allen (1995) study upwelling dynamics by conducting two-dimensional numerical experiments that resolve surface and bottom boundary layers with sophisticated turbulence closure submodels. They report that across-shelf flows are largely constrained to surface and bottom boundary layers while the alongshore flows are generally geostrophic outside $10-\mathrm{m}$ thick bottom boundary layers. The alongshore jet weakens both as stratification and bottom slopes are reduced. Nonlinear inertial forces contribute substantially at middepth shoreward of the upwelling jet where the boundary layers overlap. Extending work by Brink et al. (1987), Samelson (1997) explores the sensitivity of a linearized, two-layer shelf model to the coastal boundary condition. He argues that the shelf flow depends indirectly on the application of idealized coastal boundary conditions since frictional veering of the alongshore currents drives across-shore currents. Our observations will support this notion. Samelson (1997) finds the dependence of interior solutions on poorly understood coastal boundary conditions unsettling and calls for "... improved understanding of the dynamics that control horizontal divergence and vertical motion in the inner shelf and near-shore regions. ..." As a first step in this direction we describe the complex current structure in all three spatial dimensions on the inner shelf off New Jersey.

While the above studies all concentrate on windforced motions in isolation from other forcing, shallow shelves are often also influenced by buoyant discharges from adjacent estuaries and rivers. Münchow and Garvine (1993a) find that the estuarine discharge from Delaware Bay forces a semigeostrophic buoyancy-driven coastal current that contacts the bottom most of the time as it enters the shelf after passing through an intense tidal mixing zone. Once in contact with the bottom, friction veers the alongshore current counterclockwise with depth and causes an offshore bottom Ekman layer flux for a current flowing in the direction of Kelvin wave propagation. The frictional veering advects buoyancy across the shelf at depth and thus establishes a positive feedback to keep the water vertically mixed (Chapman and Lentz 1994). In contrast, upwelling favorable winds cause large across-shelf transports of buoyancy at the surface. For initially weakly stratified inshore waters these fluxes enhance vertical stratification because the wind stress causes offshore Ekman fluxes near the surface and onshore Ekman fluxes near the bottom (Münchow and Garvine 1993b).

Yankovsky and Garvine (1998) recently discovered another process on how buoyancy- and wind-forced motions interact on shallow stratified inner shelves. Analyzing current, sea level, and wind observations off New Jersey, they find enhanced subinertial alongshore currents with little vertical shear when buoyant Hudson coastal current waters passed their study area. They hypothesize that the buoyant waters modify the barotropic response to local winds because the buoyant waters change the horizontal velocity shear and thus the ambient vorticity distribution within which high-frequency subinertial vorticity waves propagate.

The inner shelf off New Jersey serves as an example on how upwelling dynamics on shallow shelves differ from those on deep shelves. This shelf is particularly well suited for the study of wind-forced motions and their interaction with buoyancy forced motions. Upwelling takes place predictably every summer and has been observed in satellite imagery since 1994 (Glenn et al. 1996). Tidal currents are generally weak, less than $10 \mathrm{~cm} \mathrm{~s}^{-1}$ (Münchow et al. 1992a; Münchow 2000), and contribute little to the circulation and mixing.

Unlike previous shelf studies we focus exclusively on waters less than $25 \mathrm{~m}$ deep. Numerical models often ignore this dynamically active domain (Samelson 1997) that we sampled intensely for a 3-month period with a comprehensive suite of remote, moored, and shipborne sensors. This paper integrates and condenses a small subset of these data in order to reveal a few dominant circulation patterns that statistically (not dynamically) describe about $90 \%$ of the variance. While we discuss observations qualitatively with coastal Ekman and geostrophic dynamics in mind, the primary goal is to describe the kinematics of the three-dimensional flow field from just seaward of the surf zone to the 25-m isobath. This inner shelf region extends several internal deformation radii from the coast. Our description will not answer dynamical questions; however, it provides the observational basis to guide more detailed dynamical analyses of events, processes, and dominant spatial patterns ("climatologies").

Our study is organized as follows. Section 2 introduces our study area and 1996 experiment. In section 3 we very briefly sketch the local hydrography to demonstrate the vertical and horizontal stratification within 
which our moored current meter observations are embedded. Section 4 introduces the moored current meter data in the form of depth-averaged currents and the horizontal variability of the observed flow field. In section 5 these currents are correlated with wind stress and pressure gradient forcing fields. Section 6 details the vertical variability of subtidal currents and discusses how this variability changes both across and along the inner shelf. It makes extensive use of complex empirical orthogonal functions (CEOF). We discuss our main results in section 7 and contrast them to observations from deeper shelves.

\section{The experiment}

In order to study wind-driven subtidal dynamics on a shallow shelf, we deployed current meters, pressure sensors, and thermistor strings along three across-shelf lines off New Jersey during the summer of 1996. The instruments were all moored within $30 \mathrm{~km}$ of the coast in waters less than $25 \mathrm{~m}$ deep. Figure 1 depicts the study area while Table 1 lists pertinent details of the current meters. The seven mooring locations along a northern $(\mathrm{N})$, central $(\mathrm{C})$, and southern $(\mathrm{S})$ across-shelf line are indicated as N1, N3, C1, C2, C3, S1, and S3. The labels 1,2 , and 3 indicate a location on the 12-m, 19-m, and 25-m isobath, respectively. We used three different mooring configurations to deploy four acoustic Doppler current profilers (ADCP) and eight electromagnetic current meters. The ADCPs at N3, C1, C2, and $\mathrm{C} 3$ and pressure sensors at $\mathrm{N} 1, \mathrm{~N} 3, \mathrm{~S} 1$, and $\mathrm{S} 3$ were mounted to aluminum poles that were anchored by divers more than $1 \mathrm{~m}$ into the sandy bottom. The electromagnetic current meters at $\mathrm{N} 1, \mathrm{~S} 1$, and S3 were deployed $2 \mathrm{~m}$ below surface marker buoys while deeper instruments were deployed on subsurface taut moorings.

The eight InterOcean Inc. S4 electromagnetic current meters sampled temperature, conductivity, and velocity vectors at $2 \mathrm{~Hz}$ for 5 minutes every 30 minutes. The ADCPs of RDI Inc. sampled velocity along each of four beams in vertical depth cells or bins in a variety of configurations (Table 2). The data were converted to ASCII, screened, and vector averaged for 1 hour. The data screening ensures data quality and utilizes both the correlation ( $>60$ counts) and error velocity $\left(<5 \mathrm{~cm} \mathrm{~s}^{1}\right)$ parameters of the broadband processing prior to temporal averaging. In order for an hourly average to represent valid data, we additionally require each average to have a vertical velocity less than $2.5 \mathrm{~cm} \mathrm{~s}^{-1}$ and to contain data from more than $50 \%$ of the ensembles collected during that hour. Invalid data are replaced by linear interpolation of vertically adjacent good velocity measurements. Most bins have more than 98\% valid data; however, near the surface data degrade intermittently. Here we present time series data only from those vertical locations with less than $25 \%$ invalid, but interpolated data. A harmonic analysis for the dominantly barotropic tidal currents off New Jersey (Münchow
2000; Münchow et al. 1992) indicates negligible contamination of the near-surface bins by intermittent acoustic sidelobe interference caused by the time-varying sea surface. Temporal gaps in the ADCP records of about 1 day due to servicing these moorings were filled by least squares fitting tidal and inertial currents to data from 24 hours at each end of the gap. The record from the central mooring site C2 contains a 2-week-long gap. Data from this mooring are not included in the discussion of the horizontal variability of the depth-averaged flow (section 4).

Our current meter array encloses a box with alongand across-shore dimensions of $40 \mathrm{~km}$ and $20 \mathrm{~km}$, respectively. At ADCP mooring locations N3, C1, and $\mathrm{C} 3$, we resolve the flow at vertical scales of about $1 \mathrm{~m}$ (Table 1) within less than $2-3 \mathrm{~m}$ of the bottom and generally within $4 \mathrm{~m}$ of the surface. At mooring locations N1, S1, and S3 the vertical distance between S4 current meters varies from about $4 \mathrm{~m}$ at $\mathrm{N} 1$ to $8 \mathrm{~m}$ at $\mathrm{S} 3$. Analyses of ADCP mooring data will reveal vertical correlation scales that generally exceed the coarse vertical spacing of S4 current meters. The coarsely spaced S4 current meters thus represent vertically averaged currents well.

Thermistor chains complemented the velocity observations at all mooring locations except $\mathrm{C} 2$ and $\mathrm{C} 3$ where we lost a total of three chains due to heavy barge traffic. Thermistor elements were manufactured by Vemco Inc. with a quoted accuracy of about $0.2^{\circ} \mathrm{C}$. We use wind and atmospheric pressure records from the environmental buoy EB44009 located about $100 \mathrm{~km}$ to the south of our study area. Winds there are highly correlated with winds at the Rutgers Marine Field Station less than 10 $\mathrm{km}$ from our study area. We do not use the local wind records because they contain frequent gaps. The pressure field was measured with four sensors that were custom made at Scripps Institution of Oceanography (SIO) using Paroscientific Digiquartz transducers. Their quoted range and accuracy is about $65 \mathrm{~m}$ and $0.003 \mathrm{~m}$, respectively. Less accurate pressure sensors were located along the $\mathrm{C}$ line for some of the time. All records used in this study were processed by a Lanczos lowpass filter that passes $90 \%$ and $10 \%$ of the variance at 27 and $12 \mathrm{~h}$, respectively; the half-power point is at 17 h. Throughout this paper current orientations and angles refer to true east counting angles positive counterclockwise.

The experiment also contained a survey component. The R/V Cape Henlopen and the M/V NorthStar4 sampled the three-dimensional density and velocity fields during three 6-day-long cruises in June, July, and August 1996. Here we use data only from a standard Falmouth Scientific Integrated CTD that was lowered at speeds of about $0.2 \mathrm{~m} \mathrm{~s}^{-1}$. Factory calibrations before and after the experiment indicated negligible drift, and we thus claim accuracy to be better than about $0.01^{\circ} \mathrm{C}$ for temperature, $1 \mathrm{db}$ for pressure, and $0.1 \mathrm{psu}$ for salinity. An ocean surface current radar (OSCR) unit mea- 

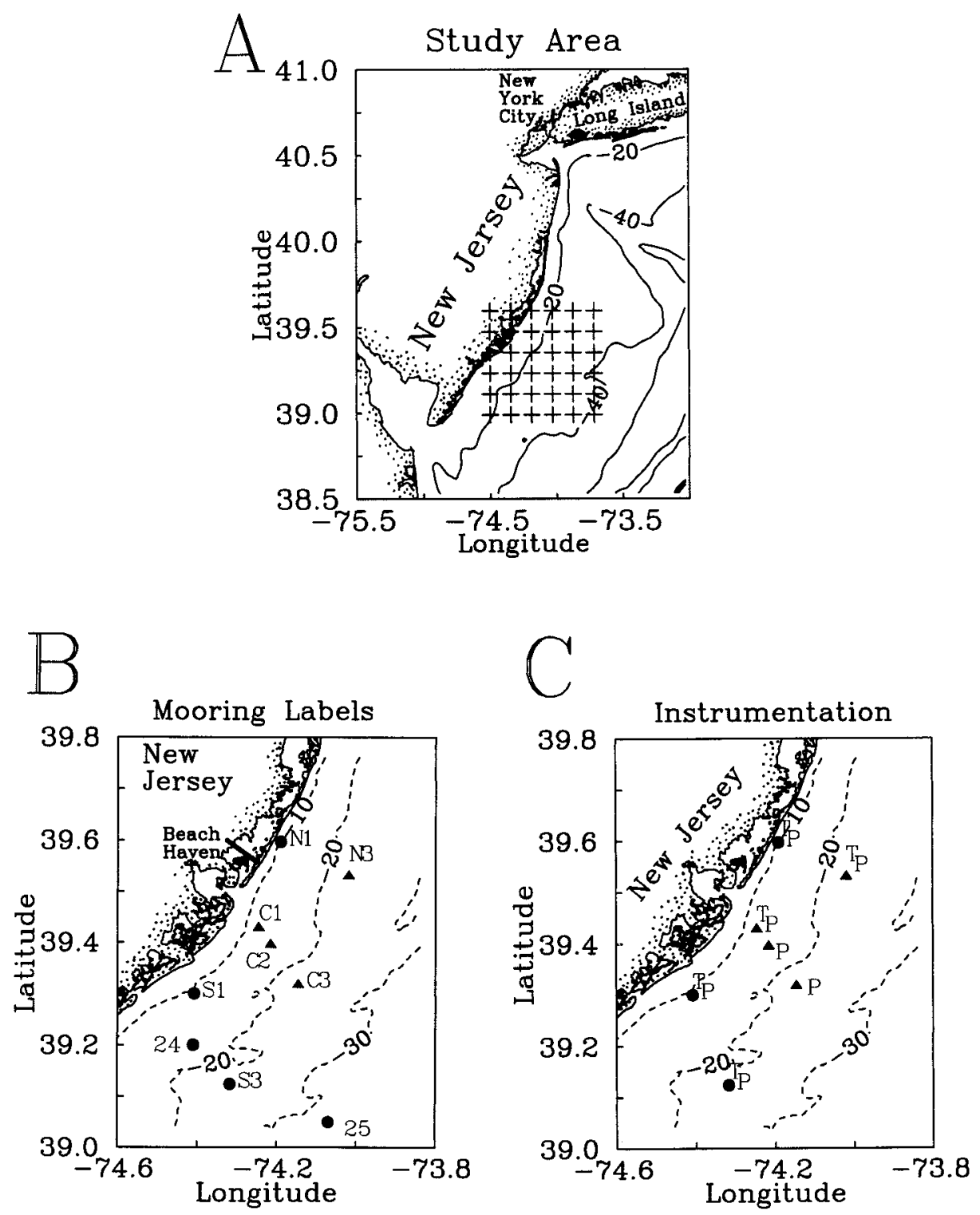

FIG. 1. Maps of (a) the study area, (b) mooring locations and labels, and (c) instrumentation over contours of bottom topography. Triangles and circles represent ADCP and S4 current meters, respectively, while labels " $\mathrm{T}$ " and "P" refer to thermistor strings and pressure sensors.

sured currents intermittently within $1 \mathrm{~m}$ of the surface. Details of the OSCR data are discussed in Chant and Münchow (1998, submitted to J. Phys. Oceanogr., hereafter CM98).

\section{Hydrography}

Frequent and strong storm systems along with surface cooling vertically mix the waters on the shelf of the Mid-Atlantic Bight during winter. Thermal heating stratifies the waters during spring and this stratification generally persists into the fall. Upwelling favorable winds, however, change both the vertical and the horizontal stratification inshore due to Ekman flux divergence near the coast. Figure 2 shows the temperature, salinity, and density fields along our central $\mathrm{C}$ line at the onset of a strong upwelling event during the first week of July. During downwelling winds the pycnoline intersects the bottom near the $15-\mathrm{m}$ isobath (Fig. 2). Seaward of the bottom front the water is strongly stratified in the vertical while shoreward it is only weakly stratified. Both temperature and salinity contribute to the dominantly horizontal stratification. The lighter inshore waters are remnants of the Hudson coastal current and salinity contributes to the density. In contrast, the pycnocline offshore corresponds to the seasonal thermocline, and salinity impacts density little. With the onset of strong upwelling favorable winds, however, the stratification 
TABLE 1. Station location details of mooring deployments. We used workhorse (WH), broadband (BB), and narrowband (NB) ADCPs.

\begin{tabular}{|c|c|c|c|c|c|}
\hline Station & Location & $\begin{array}{l}\text { Depth } \\
\text { (m) }\end{array}$ & Instrument & $\begin{array}{l}\text { Depth } \\
\text { (m) }\end{array}$ & Other instrumentation \\
\hline N1 & $\begin{array}{l}39^{\circ} 36^{\prime} 15^{\prime \prime} \mathrm{N} \\
74^{\circ} 10^{\prime} 09^{\prime \prime} \mathrm{W}\end{array}$ & 12 & $\mathrm{~S} 4$ & $\begin{array}{l}2 \\
4 \\
8\end{array}$ & $\begin{array}{l}\text { SIO pressure sensor; } \\
\text { thermistor chain }\end{array}$ \\
\hline N3 & $\begin{array}{l}39^{\circ} 31^{\prime} 57^{\prime \prime} \mathrm{N} \\
74^{\circ} 01^{\prime} 10^{\prime \prime} \mathrm{W}\end{array}$ & 25 & $\begin{array}{l}\text { WH-ADCP } \\
307 \mathrm{kHz}\end{array}$ & & $\begin{array}{l}\text { SIO pressure sensor; } \\
\text { thermistor chain }\end{array}$ \\
\hline $\mathrm{C} 1$ & $\begin{array}{l}39^{\circ} 25^{\prime} 53^{\prime \prime} \mathrm{N} \\
74^{\circ} 14^{\prime} 44^{\prime \prime} \mathrm{W}\end{array}$ & 12 & $\begin{array}{c}\text { BB-ADCP } \\
307 \mathrm{kHz}\end{array}$ & & $\begin{array}{l}\text { thermistor chain; } \\
\text { bottom S4 with } \\
\text { pressure sensor }\end{array}$ \\
\hline $\mathrm{C} 2$ & $\begin{array}{l}39^{\circ} 23^{\prime} 53^{\prime \prime} \mathrm{N} \\
74^{\circ} 12^{\prime} 56^{\prime \prime} \mathrm{W}\end{array}$ & 19 & $\begin{array}{l}\text { BB-ADCP } \\
1228 \mathrm{kHz}\end{array}$ & & $\begin{array}{l}\text { BASS tripod with } \\
\text { pressure sensor }\end{array}$ \\
\hline $\mathrm{C} 3$ & $\begin{array}{l}39^{\circ} 19^{\prime} 13^{\prime \prime} \mathrm{N} \\
74^{\circ} 08^{\prime} 46^{\prime \prime} \mathrm{W}\end{array}$ & 25 & $\begin{array}{l}\text { NB-ADCP } \\
614 \mathrm{kHz}\end{array}$ & & $\begin{array}{l}\text { bottom S4 with pressure } \\
\text { sensor }\end{array}$ \\
\hline $\mathrm{S} 1$ & $\begin{array}{l}39^{\circ} 18^{\prime} 07^{\prime \prime} \mathrm{N} \\
74^{\circ} 24^{\prime} 28^{\prime \prime} \mathrm{W}\end{array}$ & 12 & $\mathrm{~S} 4$ & $\begin{array}{r}2 \\
10\end{array}$ & $\begin{array}{l}\text { SIO pressure sensor; } \\
\text { thermistor chain }\end{array}$ \\
\hline S3 & $\begin{array}{l}39^{\circ} 07^{\prime} 27^{\prime \prime} \mathrm{N} \\
74^{\circ} 19^{\prime} 06^{\prime \prime} \mathrm{W}\end{array}$ & 25 & S4 & $\begin{array}{r}9 \\
16 \\
23\end{array}$ & $\begin{array}{l}\text { SIO pressure sensor; } \\
\text { thermistor chain }\end{array}$ \\
\hline
\end{tabular}

changes rapidly, especially inshore. The bottom density front of day 180 evolves into a surface density front three days later on day 183 that vertically stratifies the water. This event continued beyond day 185 (4 July) when, despite crowded beaches on this national holiday, we observed only three surfers in wet suits in the frigid waters at Beach Haven, New Jersey. Surface temperatures dipped below $13^{\circ} \mathrm{C}$.

We show time series of temperature in Fig. 3 along with wind vectors from EB44009. Surface temperatures increase uniformly until about day 170 (19 June 1996) when they reach almost $22^{\circ} \mathrm{C}$. A prolonged period of upwelling favorable winds from day 158 through day 170 cools the bottom waters inshore at $\mathrm{C} 1$ by more than $5^{\circ} \mathrm{C}$. At the surface, however, temperatures fluctuate without a clear cooling trend. Temperatures at the two offshore locations appear to be little affected by the wind until day 196 when Tropical Storm Bertha hit our study area. It dramatically altered the local hydrography for a few days by reducing vertical stratification both offshore and inshore; however, the water column restratified within less than 4 days after the storm has passed. Note that the response in temperature to Bertha occurs concurrently both inshore and offshore. This contrasts with upwelling events such as the one occurring on day
181 (Fig. 2). At that time temperature at the inshore mooring site $\mathrm{C} 1$ drops by almost $8^{\circ} \mathrm{C}$ at the bottom and $5^{\circ} \mathrm{C}$ at the surface. In contrast, the offshore mooring sites S3 and N3 experience cooling more slowly and then only at middepth. This suggests that either the thermocline changes its vertical position or that different waters are advected past the mooring. A companion paper will detail volume flux, heat flux, and momentum budgets to address these processes fully.

Figure 4 presents the vertical profile of record mean temperatures for a common record from day 158 (7 June) through day 222 (10 August) at the offshore stations N3, S3, and at the inshore station C1. At the offshore stations the mean profiles indicate a three-layered system (Fig. 4a). A bottom mixed layer consists of water generally less than $10^{\circ} \mathrm{C}$ at depths below $18 \mathrm{~m}$. The surface mixed layer with mean temperatures above $18^{\circ} \mathrm{C}$ occupies the top 5-10 m of the water column. Between these two layers the thermocline constitutes an intermediate layer that extends from about $8-\mathrm{m}$ to $18-\mathrm{m}$ depth. Data from synoptic hydrographic sampling (Fig. 2) suggests an 5-m-thick thermocline where the vertical temperature gradient exceeds $2^{\circ} \mathrm{C} / \mathrm{m}$. Still, a 5-m-thick thermocline constitutes about $20 \%$ of the entire water column. The mean temperature profile inshore at $\mathrm{C} 1$

TABLE 2. Deployment details of the ADCPs.

\begin{tabular}{|c|c|c|c|c|c|c|c|}
\hline Station & Model & $\begin{array}{c}\text { Frequency } \\
(\mathrm{KHz})\end{array}$ & $\begin{array}{l}\text { Beam angle } \\
\text { (deg) }\end{array}$ & Mode & $\begin{array}{l}\text { Depth bin } \\
\quad(\mathrm{m})\end{array}$ & $\begin{array}{c}\text { Pings/ } \\
\text { ensemble }\end{array}$ & $\begin{array}{l}\text { Time between } \\
\text { ensembles } \\
(\mathrm{min})\end{array}$ \\
\hline N3 & WH & 307 & 20 & 1 & 1.00 & 30 & 5 \\
\hline $\mathrm{C} 1$ & BB & 307 & 20 & 1 & 1.00 & 30 & 5 \\
\hline $\mathrm{C} 2$ & BB & 1228 & 20 & 4 & 0.25 & 60 & $0.5^{*}$ \\
\hline $\mathrm{C} 3$ & NB & 614 & 30 & N/A & 1.00 & 120 & 5 \\
\hline
\end{tabular}

* Burst sampling for 15 minutes every hour. 

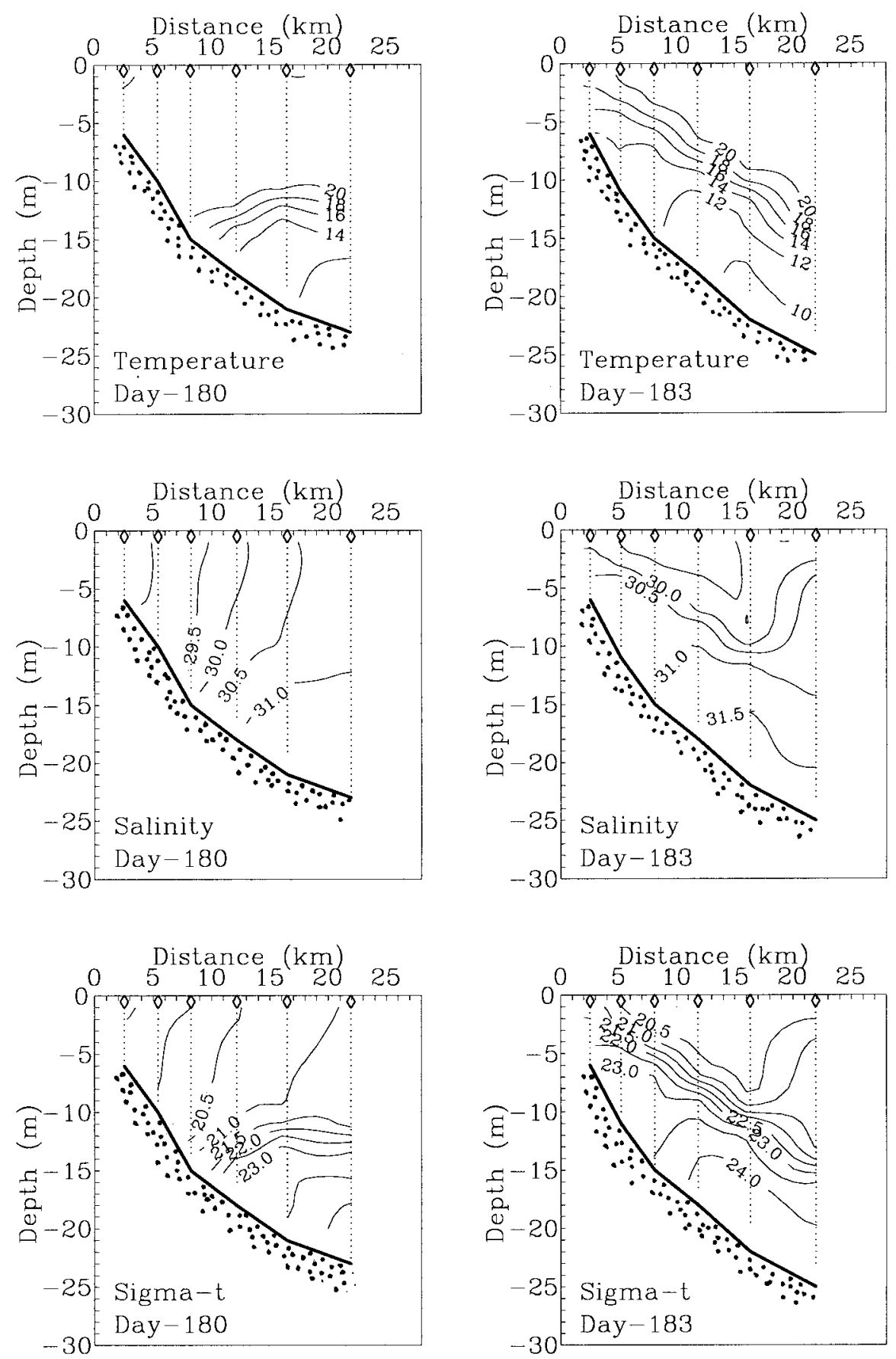

FIG. 2. Temperature, salinity, and density section along central mooring line $\mathrm{C}$ prior to and during an upwelling event on day 180 (29 June) and day 183 ( 2 July) of 1996. Note the presence of fresher waters inshore on day 180 and its offshore location on day 183. Note also that the vertical stratification inshore increases as a result of the upwelling.

contrasts with the offshore profiles at $\mathrm{N} 3$ and $\mathrm{S} 3$. A uniform temperature gradient indicates a single 8-mthick partially mixed layer. Data from synoptic hydrographic sampling (Fig. 2) generally reveal weak vertical stratification with absolute values changing rapidly at this location. Only during strong upwelling events do waters inshore of the $15-\mathrm{m}$ isobath stratify when cold bottom waters advect onshore, a thermal bottom front detaches from the bottom, slopes toward the surface (Fig. 2), and occasionally breaks to the surface.

Typical summer temperatures near the bottom on the middle and outer shelf off New England vary from about 

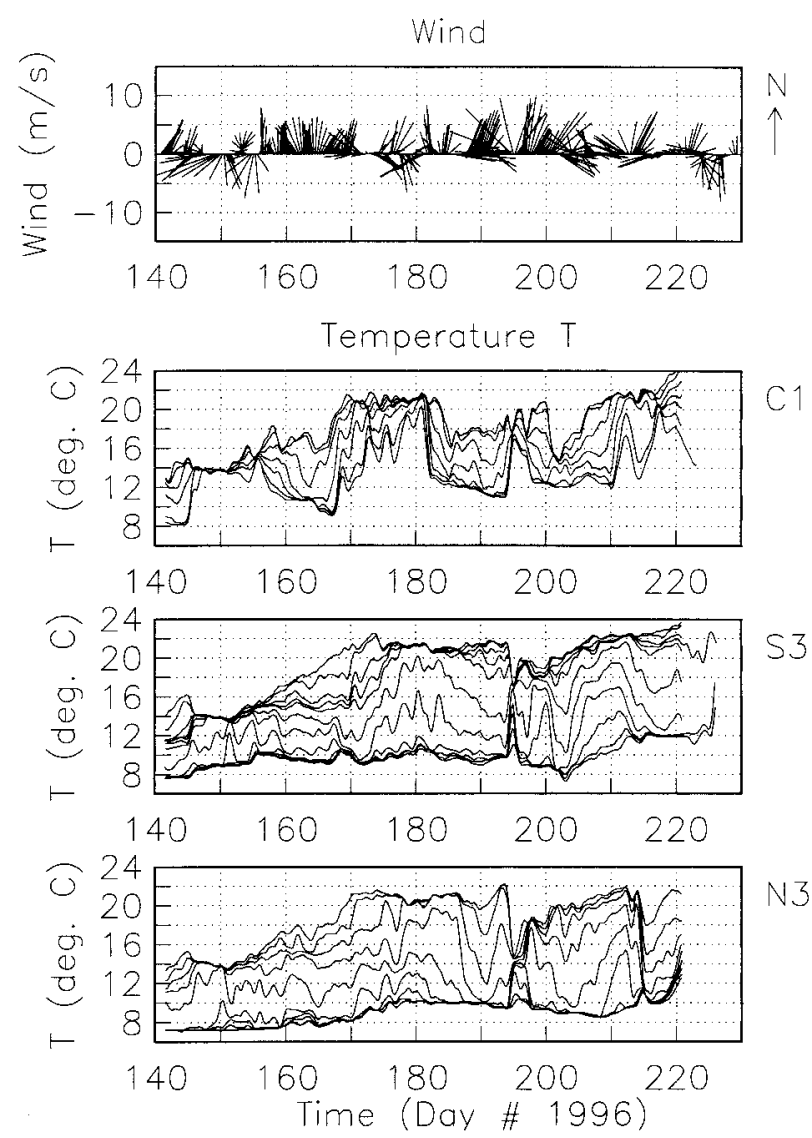

FIG. 3. Low-passed filtered time series of (top to bottom) wind vectors at EB44009 and temperatures at C1, S3, and N3.

$7^{\circ} \mathrm{C}$ in June to about $10^{\circ} \mathrm{C}$ in August and these waters are commonly referred to as "cold pool" waters (Houghton et al. 1982). In our study area summer bottom temperatures drop below $9^{\circ} \mathrm{C}$ at N3 and $10^{\circ} \mathrm{C}$ at S3 and match properties of "cold pool" waters. These wa- ters originate from the Nantucket Shoal area to the north and are advected southward at speeds of about $2 \mathrm{~cm} \mathrm{~s}^{-1}$ (Houghton et al. 1982). Our study area thus features a bottom front associated with the inshore edge of the "cold pool."

\section{Depth-averaged flow}

Figure 5 depicts time series of the depth-averaged flow at the six mooring locations along with, for comparison, the wind vectors. Except at N1 the magnitude of the inshore flow exceeds the offshore flow by about $50 \%$. Instantaneous currents offshore generally remain below $10 \mathrm{~cm} \mathrm{~s}^{-1}$ (Fig. 5a) and reveal little alongshore variation in speed and direction. In contrast, instantaneous flows at $\mathrm{C} 1$ and $\mathrm{S} 1$ exceed $20 \mathrm{~cm} \mathrm{~s}^{-1}$ during strong events on days 165-180 and 195-200, respectively (Fig. $5 b)$. The alongshore variability of depth-averaged inshore currents is larger than offshore also. While flows at the northern station $\mathrm{N} 1$ never exceed $15 \mathrm{~cm} \mathrm{~s}^{-1}$, the southern stations reveal frequent flows in excess of 20 $\mathrm{cm} \mathrm{s}^{-1}$ with the strongest flows at the central station $\mathrm{C} 1$. Note also that the flow does not appear to correlate strongly with the local winds. During a period of sustained upwelling favorable winds from day 158 to day 170 , for example, very strong flows reaching $20 \mathrm{~cm} \mathrm{~s}^{-1}$ at $\mathrm{C} 1$ and $\mathrm{S} 1$ oppose the winds from day 165 to day 170. Other processes besides the local winds thus provide a strong forcing for the flow. Using time series of density from the S4 current meters at N1 and S1, Yankovsky and Garvine (1998) demonstrate that relatively fresh waters pass through our study area. Buoyancy from the intermittent Hudson coastal current, such as shown in Fig. 2, constitutes an additional forcing that strongly modifies the local wind-driven response. We will return to this forcing after we discuss the temporal evolution of spatial flow field patterns.

Table 3 summarizes the statistics of the depth-aver-
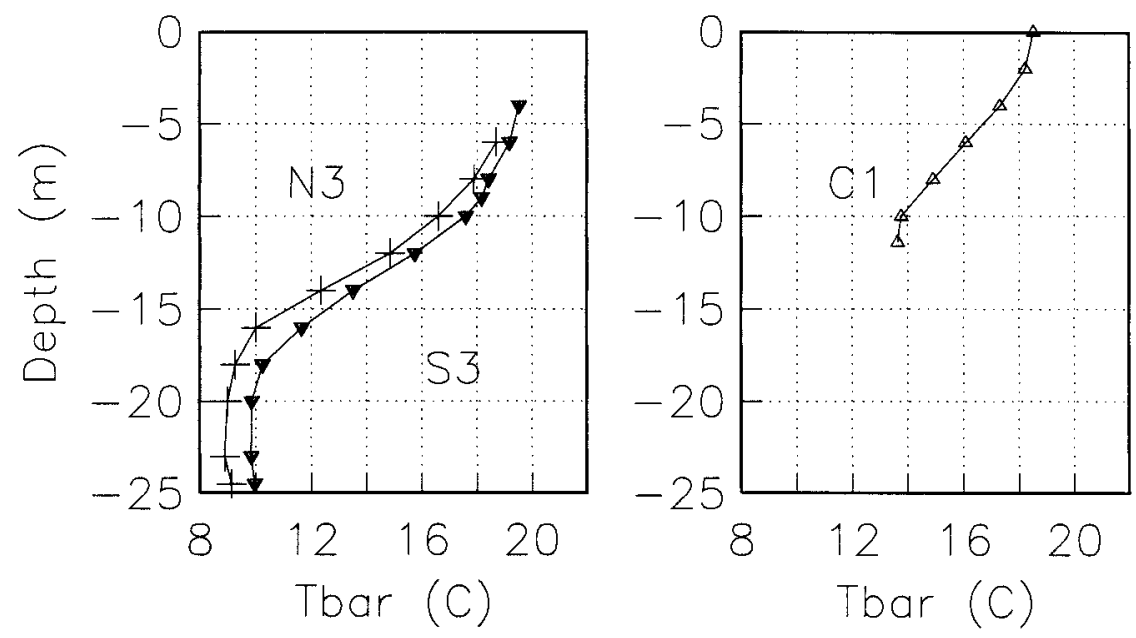

FIG. 4. Vertical structure of time-averaged temperature profiles at C1 (right panel), and at N3 and S3 (left panel) for day 158-222. 

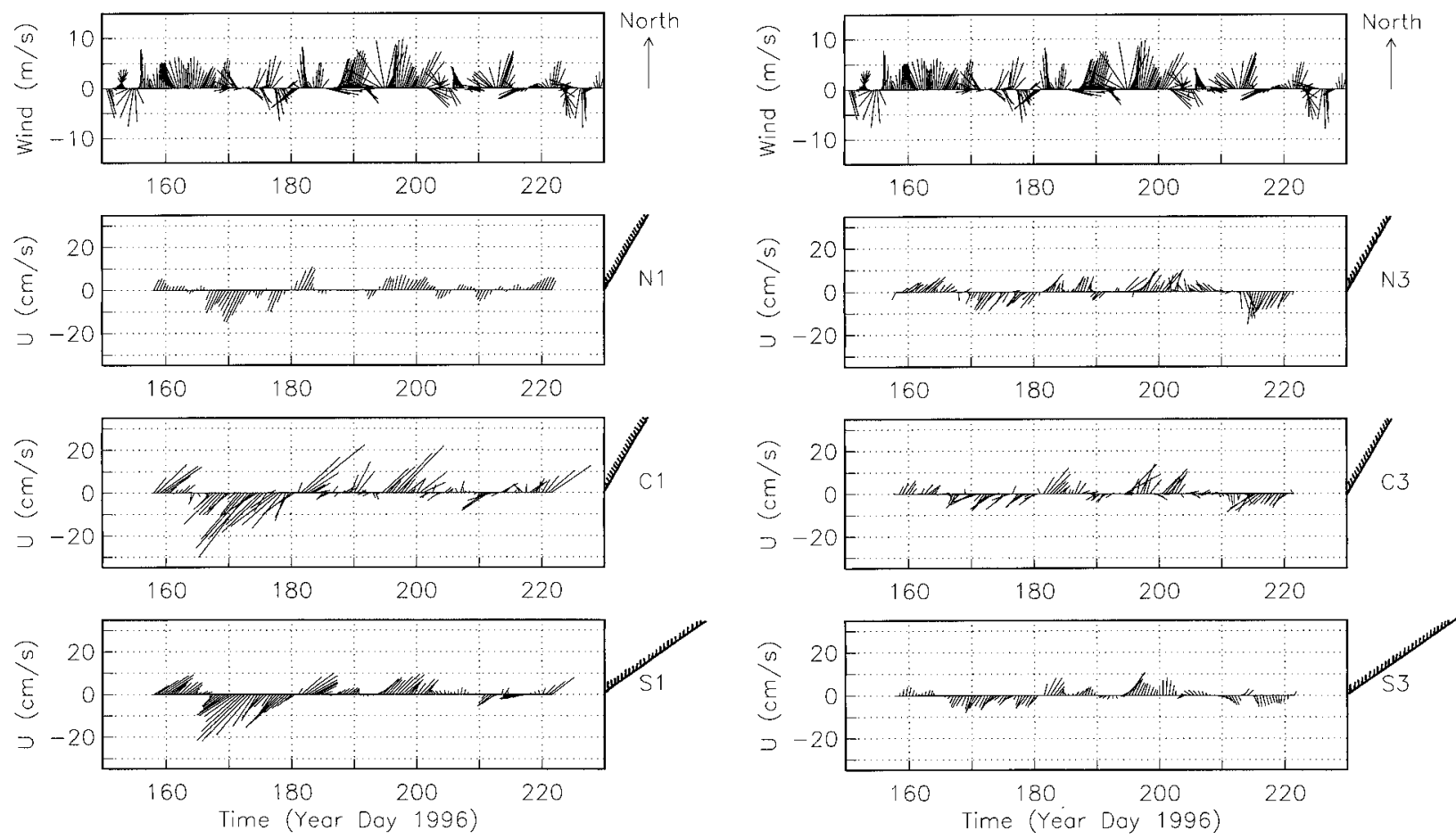

FIG. 5. Time series of depth-averaged currents along with wind vectors. Station labels are shown to the right of each velocity time series (see Fig. 1 for locations) along with the orientation of the coast.

aged flow field that we depict in Fig. 6. It reveals weak record mean flows $\left(<5 \mathrm{~cm} \mathrm{~s}^{-1}\right)$ that, while barely significant, nevertheless indicate a spatially uniform pattern that reflects a snapshot of seasonal variability. Inshore the mean flow is to the south along the $10-\mathrm{m}$ isobath (Fig. 6a) while offshore it is weaker yet but mostly across-shore. The pattern of onshore flow in the north and south with offshore flow in the center of our array is perhaps fortuitous but it is consistent with hydrographic features during strong upwelling events (not shown). The standard deviations about the weak mean currents are much larger. Figure $6 \mathrm{~b}$ shows the magnitude and orientation of the principal axes that are the eigenvectors of the Reynolds stress tensor of velocity fluc- tuations (Kundu and Allen 1976). Major axis orientations are always along isobaths with magnitudes that vary from 4 to $12 \mathrm{~cm} \mathrm{~s}^{-1}$. The southern inshore stations $\mathrm{C} 1$ and $\mathrm{S} 1$ have stronger principal axes than the northern and offshore stations. Minor axes are generally weak, about $10 \%-30 \%$ of the major axes.

In order to delineate the dominant horizontal structure of the velocity fluctuations we next estimate empirical orthogonal functions (EOFs). The temporal mean shown in Fig. 6a is not part of the analysis as it is removed from each of the $N=6$ time series. An EOF analysis decouples spatial variability $\phi_{n}(x)$ from temporal variability $A_{n}(t)$ as a set of $n=1,2, \cdots, N$ statistical "modes"; that is,

TABLE 3. Basic statistics. The decorrelation timescale $T_{D}$ gives the range from generally low surface to larger bottom values. RMAJ and ORIE refer to the major axis amplitude and its orientation counterclockwise from true east, respectively. $C_{12}$ represents the correlation with the wind stress, $\sigma$ is the normalized correlation according to Sciremammano (1979), which is used to determine significance levels.

\begin{tabular}{cccccccc}
\hline \hline Mooring & $\begin{array}{c}T_{D} \\
(\text { days })\end{array}$ & $\begin{array}{c}\text { RMAJ } \\
\left(\mathrm{cm} \mathrm{s}^{-1}\right)\end{array}$ & $\begin{array}{c}\text { ORIE } \\
(\mathrm{deg})\end{array}$ & $\begin{array}{c}U_{\mathrm{bar}}(\mathrm{dir}) \\
\left(\mathrm{cm} \mathrm{s}^{-1}\right) \\
(\mathrm{deg})\end{array}$ & $\begin{array}{c}\text { CEOF 1 } \\
(\% \text { var })\end{array}$ & $\begin{array}{c}\text { CEOF 2 } \\
(\% \text { var })\end{array}$ & $C_{12}\left(C_{12} / \sigma\right)$ \\
\hline N1 & $1.0-1.7$ & 5.3 & 65 & $2.0(-131)$ & 92 & 5 & $0.30\left(2.3^{\mathrm{b}}\right)$ \\
N3 & $0.6-1.2$ & 6.4 & 60 & $0.6(70)$ & 80 & 15 & $0.41(3.0)$ \\
C1 & $1.0-1.4$ & 12.8 & 43 & $3.8(-115)$ & 95 & 4 & $0.43(3.3)$ \\
C2 & $1.0-1.7 \mathrm{a}$ & $8.8^{\mathrm{a}}$ & $42^{\mathrm{a}}$ & & $88^{\mathrm{a}}$ & $8^{\mathrm{a}}$ & \\
C3 & $0.7-1.4$ & 6.8 & 43 & $0.8(-50)$ & 83 & 11 & $0.47(3.6)$ \\
S1 & $1.3-2.9$ & 10.0 & 41 & $4.2(-169)$ & 97 & 3 & $0.37(2.6)$ \\
S3 & $1.2-1.9$ & 4.4 & 64 & $2.4(107)$ & 82 & 14 & $0.54(3.9)$ \\
\hline
\end{tabular}

${ }^{\text {a }}$ Not part of the common period of days $158-222$.

${ }^{b}$ Not significant at $99 \%$ level of confidence. 

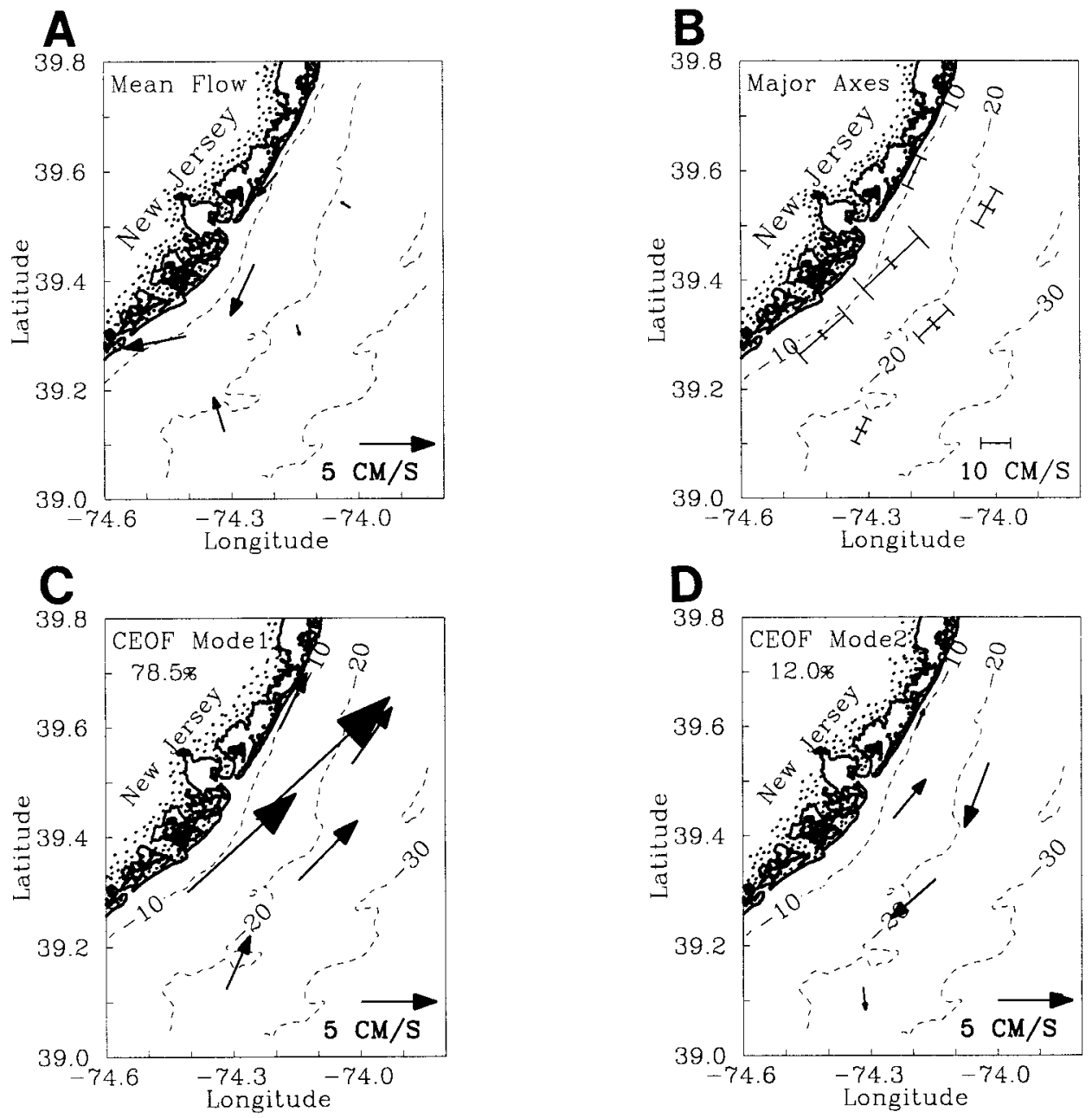

FIG. 6. Maps of depth-averaged (a) mean current vectors, (b) principal axes, (c) pattern of complex EOF 1 (78.5\% of total variance), and (d) pattern of complex EOF 2 (12.0\% of total variance).

$$
U(x, t)=\sum_{n} A_{n}(t) \cdot \phi_{n}(x) .
$$

Each mode explains a fraction of the total variance and is uncorrelated (orthogonal) to any other "mode." An EOF analysis orders data efficiently such that the fewest "modes" explain more variance than any other decomposition (Davis 1976). For velocity all properties in Eq. (1) are complex as the decomposition is that of a vector. Kundu and Allen (1976) describe the method and its application elegantly in detail. Complex EOF analysis thus avoids the artificial separation of along- and acrossshelf EOF modes. Since the temporal and spatial modes $A_{n}(t)$ and $\phi_{n}(x)$ are both complex, they both have magnitude (speed) and orientation (direction). The orientation of temporal amplitudes and spatial patterns are relative to an arbitrary reference (Kundu and Allen 1976). To facilitate a physical interpretation, we follow Merrifield and Winant (1989) and rotate the spatial pattern into the frame of the semimajor principal axis of the corresponding modal time series. We furthermore normalized our CEOF solutions such that the temporal amplitudes have a nondimensional variance of 1 and, therefore, each spatial pattern carries units in centimeters per second. We can then add and subtract the mean vector at each location to and from each mode to discuss different "climatologies" of the flow field (Harms and Winant 1998). We subsequently present and interpret results of the CEOF analysis throughout this study only if the modes are distinct and statistically significant. North et al. (1982) provide mode selection rules and significance tests that we use throughout this study. Further EOF details, a discussion of error estimation, and a computed example of error estimation are all deferred to the appendix.

The first CEOF mode of the depth-averaged currents explains more than $78 \%$ of the total variance. Figures $6 \mathrm{c}$ and $6 \mathrm{~d}$ represent the spatial patterns of the first and second CEOF, respectively. The spatial pattern of mode 1 indicates a dominantly alongshelf flow everywhere. The ratio of semiminor to semimajor axes of the tem- 

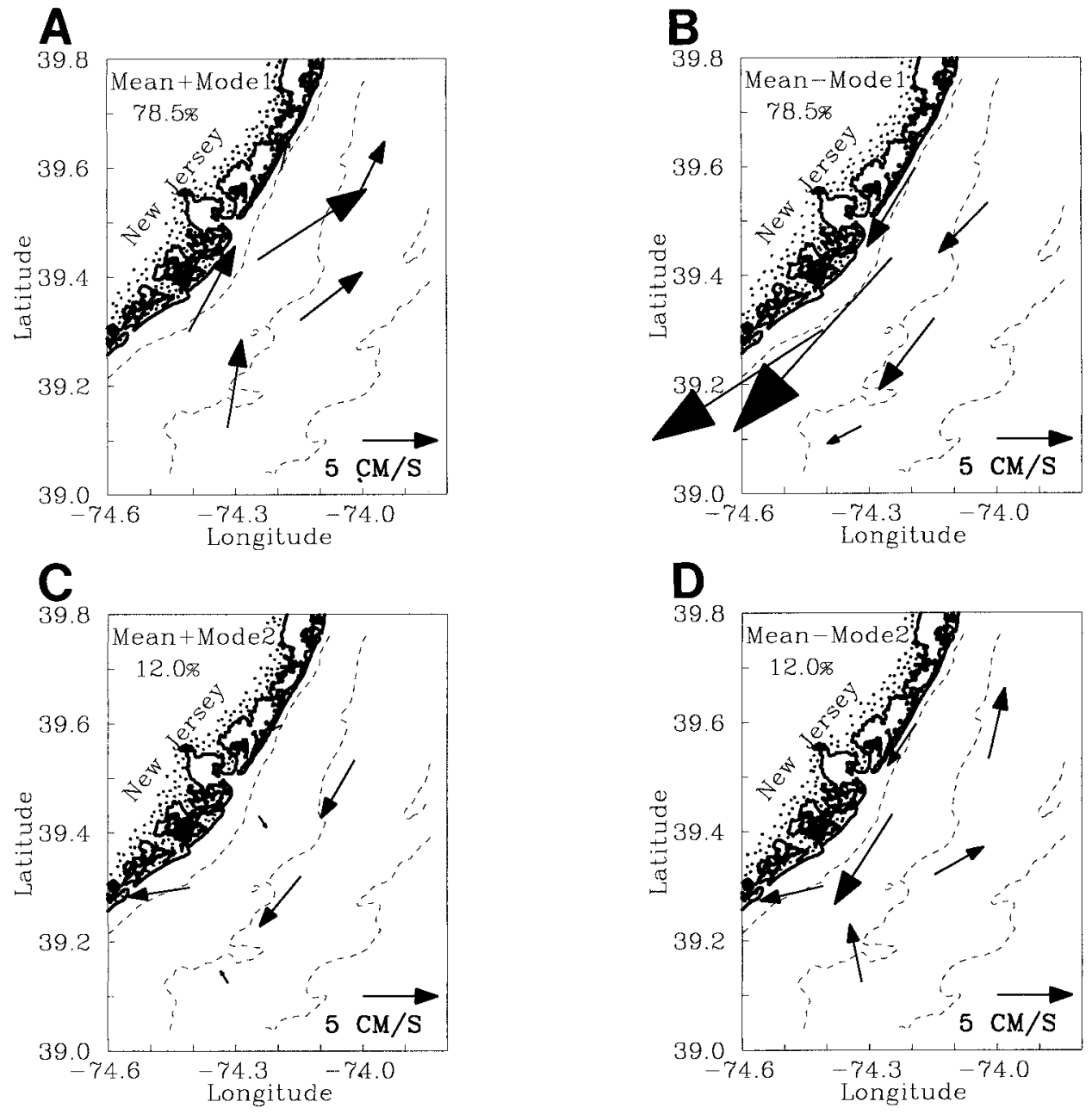

FIG. 7. "Climatologies" of the flow field. We depict the velocity field resulting from (a) mean + CEOF1, (b) mean - CEOF1, (c) mean + CEOF2, and (d) mean - CEOF2.

poral amplitude time series is about 0.12 and mode 1 thus represents an almost rectilinear flow. The flow pattern also indicates substantial lateral current shear at the central and southern sections as the inshore current exceeds the offshore current by almost a factor of 2 . We find little or no lateral shear at the northern section. This contrasts with the flow pattern of mode 2 that explains $12 \%$ of the total variance. In mode 2 the flow at offshore locations is stronger and opposes the inshore flow at all times. At S3 it contains a sizable across-shore component while it does not contribute to the flow at S1. The semiminor axis of mode 2 is large and reaches almost a third of the semimajor axis.

How can we interpret these purely statistical modes physically? Following Harms and Winant (1998), we present in Fig. 7 four different "climatologies" by adding and subtracting the $n$th modal pattern $\phi_{n}(x, y)$ from the time-averaged mean flow $U_{\mathrm{bar}}(x, y)$. Note that the actual velocity field described by mode $n$ is $A_{n}(t) \cdot \phi_{n}(x, y)$ and that the amplitude can be both pos- itive and negative. The first two CEOFs thus can represent four different scenarios depending on the sign of $A_{n}(t)$. [Formally we should consider its orientation also since $A_{n}(t)$ is complex; however, we here and in the remainder of this study limit our discussion to the major axis of $A_{n}(t)$.] These four scenarios suggest distinctive physical idealizations of the flow field. The distribution of $U_{\mathrm{bar}}+\phi_{1}$ indicates a meandering flow in the direction of upwelling favorable winds (Fig. 7a). The lateral shear is small. The modal time series $A_{1}(t)$ (Fig. 8) indicates three positive $\left(A_{1}(t)>0\right.$; upwelling) events with amplitudes that exceed 1.5 on day 159 (8 June), day 181 (30 June), and day 196 (15 July). These are indeed times when the temperature and wind records indicate intense upwelling (Fig. 3). After each large positive mode-1 event (upwelling), mode 2 becomes negative $\left(A_{2}(t)<\right.$ -1 , Fig. $8 \mathrm{~b})$. The correlation between temporal amplitudes of mode 1 and mode 2 is zero at zero lag by construction; however, at a lag of about 4 days we find the magnitude of the complex correlation coefficient 
A

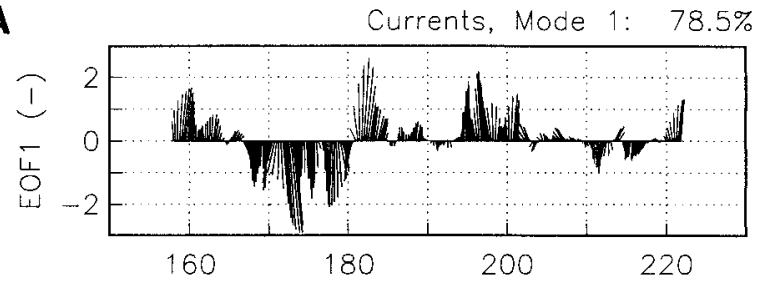

B

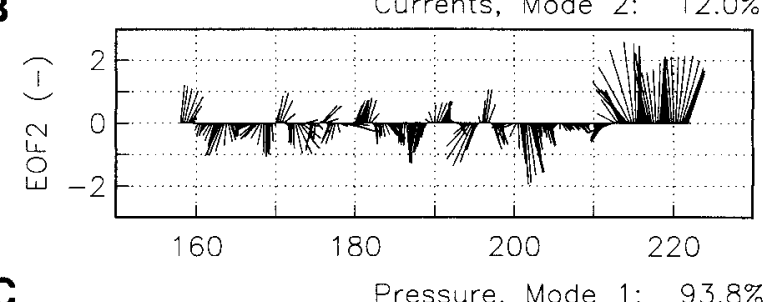

C

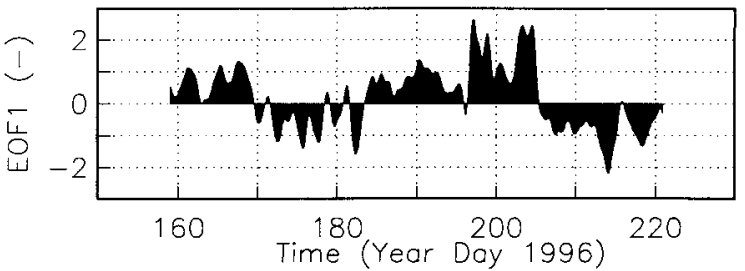

FIG. 8. Time series of amplitudes of (a) current CEOF mode 1 and (b) mode 2 along with (c) pressure EOF mode 1. The time series are all nondimensional standard deviations; time series are scaled to have a total variance of 1 . Positive values for the pressure EOF correspond to sea level that is lower inshore than offshore (upwelling favorable).

$c_{12}=0.31$. This vector correlation is not significant using an algorithm suggested by Sciremammano (1979). Repeating the CEOF analysis for surface current observations, we find virtually identical patterns that explain similar variances (not shown); however, now a significant ( $90 \%$ confidence) correlation $c_{12}=0.45 \mathrm{im}$ plies that mode 1 leads mode 2 by about 5 days. The lagged correlation suggests a temporal sequence, that is, following the positive phase of mode 1 (upwelling), the negative phase of mode 2 exhibits cyclonic tendencies as the inshore flow opposes the offshore flow (Fig. $7 d)$. This lateral shear probably relates to relaxation after the meandering upwelling circulation (Fig. 7a). CM98 discuss the evolution of such an event from day 200 to day 210 in detail. In section 6 we will suggest that the depth-dependent response to such events is much stronger than the depth-averaged response discussed here.

After relaxation the wind may turn either toward upwelling (Fig. 7a; positive phase of mode 1) or downwelling (Fig. 7b; negative phase of mode 1). The downwelling pattern $U_{\text {bar }}-\phi_{1}$ combines both wind and buoyancy forcing as winds from the north support the downstream advection of buoyant waters. We find only a single strongly negative phase of mode $1\left(A_{1}(t)<-2\right)$ near day 173 (22 June). This event lasts for about two weeks and represents the most persistent feature in our 3 -month record. Furthermore, the lateral shear is large since the inshore flow exceeds the offshore flow by a factor of 2 and more. In contrast to $U_{\text {bar }}+\phi_{1}$, the flow represented by $U_{\text {bar }}-\phi_{1}$ (Fig. 7b) does not meander and is uniform in the direction of downwelling favorable winds and/or buoyancy forcing. Based on these observations, extensive survey data (not shown), and Yankovsky and Garvine (1998), we hypothesize that CEOF mode 1 contains a buoyancy-forced component when $A_{1}(t)<0$ and a potentially unstable upwelling favorable wind forced component when $A_{1}(t)>0$.

The CEOF analysis does not separate wind from buoyancy forcing, and we suspect that the two forcing mechanisms are coupled. Yankovsky and Garvine (1998) use time series of density, sea level, and selected velocity data to show that the Hudson coastal current passed our study area frequently in the summer of 1996. The presence of buoyant waters modifies the barotropic response to local winds because the buoyant flow changes the horizontal shear, the ambient vorticity distribution, and thus the dynamical medium within which highfrequency transient wind-forced vorticity waves propagate (Yankovsky and Garvine 1998). Our results support the presence of strong lateral shear in the depth-averaged fields during downwelling/buoyancy events $\left[A_{1}(t)<0\right]$. It thus should not surprise one that the statistical CEOF analysis does not separate buoyancy from wind forced motions as the two are coupled physically.

\section{Pressure gradient and wind forcing}

The response of the Mid-Atlantic Bight to wind stress and other forcing will also result in pressure gradients. From day 158 to day 172 and day 192 to day 220 we measured subsurface pressure at every location of our mooring array. The temporal EOF amplitudes of the gappy record are indistinguishable from the temporal EOF amplitudes of gap-free data using only the four SIO pressure sensors. We thus feel justified to use the mode-1 spatial pattern from the gappy record of seven sensors along with the mode- 1 temporal amplitudes from the gap-free record (Fig. 8c). The variance explained for the gappy record $(94.7 \%)$ is similar to that of the gap-free record (93.8\%). Since the SIO sensors are accurate to within $0.3 \mathrm{~cm}$, pressure differences larger than $0.6 \mathrm{~cm}$ represent a physically meaningful signal.

The spatial EOF pattern (Fig. 9) reveals height differences both along and across the inner shelf that are internally consistent with dynamical expectations. For a nondimensional temporal amplitude of 1 , the acrossshore slope varies from $0.7 \mathrm{~cm}$ across the $\mathrm{N}$ line to 1.7 $\mathrm{cm}$ across both the $\mathrm{C}$ and $\mathrm{S}$ lines. Recall that the fluctuating depth-averaged flow in the south and inshore was almost a factor 2 stronger than the flow in the north and offshore (Fig. 6b and Table 3). Concurrently, the alongshore height differences varies from $1.1 \mathrm{~cm}$ inshore to $0.7 \mathrm{~cm}$ offshore. We next discuss temporal aspects of this first EOF, correlate it with both wind stress and depth-averaged current time series, and close this 


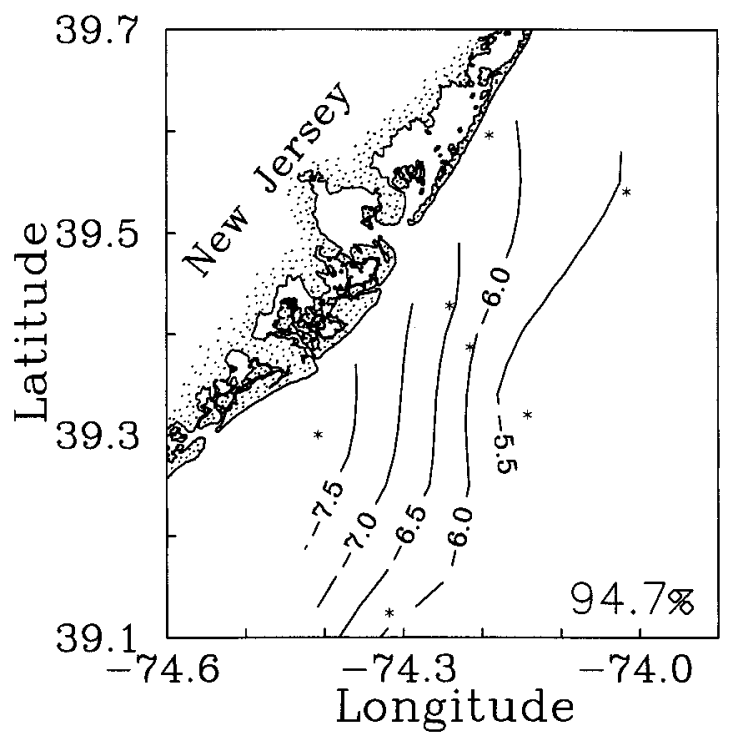

FIG. 9. Spatial pattern of EOF mode 1 of pressure fluctuation that explains $94.7 \%$ of the total variance. The units are in centimeters and suggest both an across-shore and an alongshore sea surface height difference in our study area. The stars indicate measurement locations.

section with a brief discussion of its implications for the momentum balance.

The first pressure EOF lags the wind stress by about 1.5 days when the maximum correlation reaches 0.48 . In contrast, the first current CEOF lags the wind stress by $6 \mathrm{~h}$ when the correlation reaches 0.46 . Both correlations are significant at the $95 \%$ confidence level using the algorithm suggested by Sciremammano (1979). The algorithm takes into account the decorrelation timescale $T_{D}$; that is,

$$
T_{D}=\int C_{x x}(t) C_{y y}(t) d t \approx 2 \text { days, }
$$

where $C_{x x}(t)$ and $C_{y y}(t)$ are autocorrelations of the wind stress (along its principal axis) and the first pressure EOF (current CEOF), respectively, as a function of lag time $t$ (Davis 1976). In practice the integral is replaced by a finite sum that we truncated at $t=30$ days.

A coherence analysis in the frequency domain (not shown) suggests that the pressure EOF correlates significantly (95\% confidence) with the wind stress at two distinct timescales. At a 10-20-day timescale about $45 \%$ of the pressure variance in the first mode is explained by the local winds at zero lag while at a 2-5-day timescale the wind explains almost $50 \%$ of the pressure variance at a lag of about 1-2 days. A distinct spectral gap exists between these two timescales. It thus appears that while the wind stress forces currents almost instantaneously, the sea surface takes 1-2 days to adjust to the currents that set up the across- and alongshore pressure gradients.

The correlations in both time and frequency domains between depth-averaged currents, pressure EOF, and winds suggest simple dynamical balances; that is, we can interpret a linear regression between alongshore currents $U(t)$ and the nondimensional temporal amplitude of the pressure EOF $p(t-\tau)$ in the form of

$$
U(t)=a+b \cdot p(t-\tau)
$$

as an approximation to the geostrophic across-shore momentum balance

$$
U=-f^{-1} g \partial_{y} \eta
$$

where $g \partial_{y} \eta=\rho^{-1} \partial_{y} P$ is the across-shore pressure gradient, $\rho$ is the density, $g$ is the gravitational constant, and $f$ is the Coriolis parameter. The lag time $\tau$ is $24 \mathrm{~h}$. We estimate a section-averaged alongshore velocity $U(t)$ by rotating the depth-averaged currents at $\mathrm{C} 1$ and $\mathrm{C} 3$ into the direction of the semimajor axis (Table 3 and Fig. 6b) and average these alongshore flows at $\mathrm{C} 1$ and $\mathrm{C} 3$ at each time. The resulting coefficients are $a=-2.8$ $\pm 0.45 \times 10^{-2} \mathrm{~m} \mathrm{~s}^{-1}$ and $b=5.7 \pm 0.37 \times 10^{-2} \mathrm{~m}$ $\mathrm{s}^{-1}$; the uncertainties represent $95 \%$ confidence limits of parameter estimation in multiple regression (Fofonoff and Bryden 1975). The coefficient $a$ represents the "mean" velocity due to an unknown "mean" pressure gradient. The coefficient $b$, however, represents the weight of the temporal amplitude $p(t-\tau)$, which for a geostrophic flow should be

$$
b \approx f^{-1} g \delta p / \delta y=9.3 \pm 3.58 \times 10^{-2} \mathrm{~m} \mathrm{~s}^{-1},
$$

where $\delta p=1.6 \pm 0.6 \mathrm{~cm}$ and $\delta y=15 \mathrm{~km}$ are the spatial sea level difference and distance, respectively, between $\mathrm{C} 1$ and $\mathrm{C} 3$ (Fig. 9). While the agreement is not perfect, it is within the uncertainties of the measurements and statistical curve fitting. A unit pressure EOF amplitude thus represents a depth-averaged geostrophic alongshore current of about $9 \mathrm{~cm} \mathrm{~s}^{-1}$. We note, however, that the pressure EOF $p(t-\tau)$ explains only about $39 \%\left(c_{12}=0.62\right)$ of the variance of the sectionaveraged velocity $U(t)$. The correlation between these two series agrees well with similar correlations listed in Table 3. We also note that the regression underestimates the fluctuating pressure gradient by about $60 \%$.

In summary, we conclude that the time-varying across-shore sea level slope suggested by the first EOF is consistent with a geostrophic response. Upshelf currents during upwelling favorable winds coincide with a decrease of sea level near the coast consistent with across-shelf geostrophy. They also tend to increase sea level toward the north where Long Island blocks the alongshore flow. The reverse holds for downwelling favorable winds and/or downshelf flow of the Hudson coastal current.

\section{Vertical variability}

Currents on the inner shelf off New Jersey exhibit considerable vertical shear and veering. This result will emerge from "mean" along- and across-shelf currents on the central $\mathrm{C}$ line, from principal component analysis 

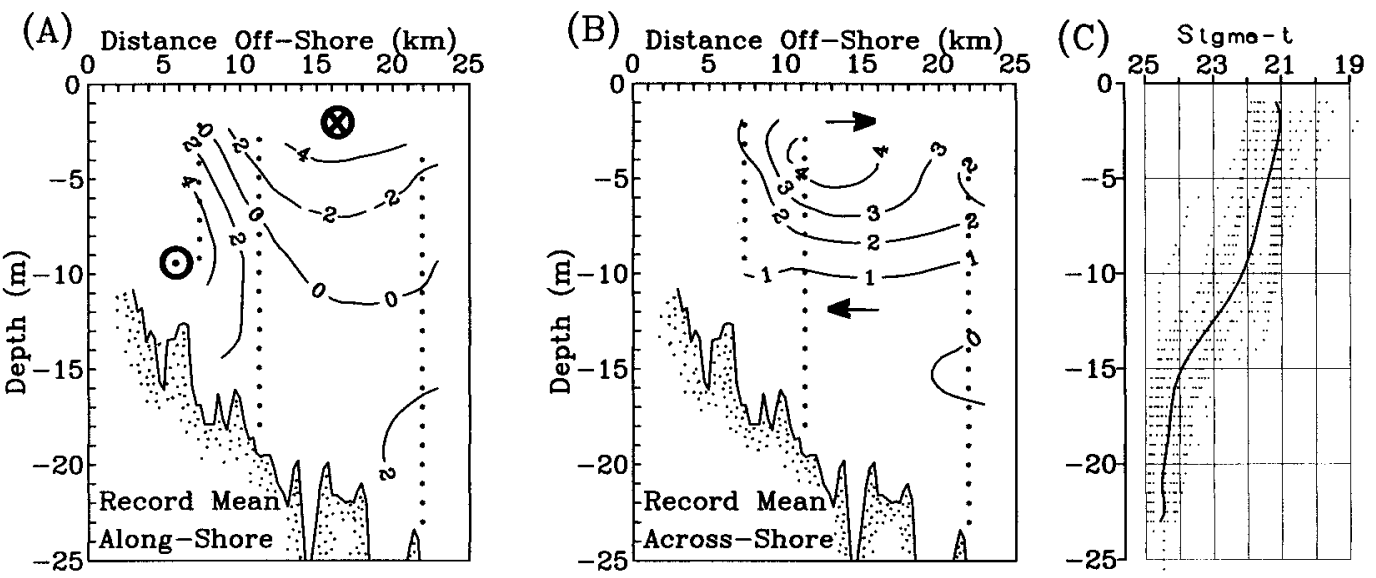

FIG. 10. Record "mean" (a) alongshore and (b) across-shore currents along the central C line. Positive currents are downshelf and offshore for the along- and across-shore components, respectively. The vertical stratification offshore is shown in (c) where the symbols indicate $\sigma_{t}$ values from 16 CTD profiles at C3 while the solid line is a polynomial fit to the data.

of current ellipses, and, finally, from complex EOF analyses. In this section we proceed from a snapshot of seasonal variability (i.e., the "record mean") to daily and weekly variability of current profiles, sections, and maps. This procession in temporal and spatial dimensionality will aid the interpretation of the main feature, which is the large veering of currents with depth at all locations. To minimize the ambiguity between acrossand alongshore motions, we present most of our results in terms of speed and direction (veering).

The across-shore variation of the mean current for the $\mathrm{C}$ line represents a snapshot of seasonal variability during the summer months. The common record here is 42 days long from day 158 to day 222 with a gap from day 172 to day 192. For this period the mean alongshore current (along the principal axis of the depthaveraged flow, Table 3) indicates a surface-intensified, laterally sheared flow to the north in the direction of the generally upwelling favorable winds (Fig. 10a). At depth, and especially close to shore, the flow is in the opposite direction. An alongshore barotropic pressure gradient opposing the wind stress preferentially inshore could explain this feature. The pressure EOF shown in Fig. 9 supports the hypothesis that such forcing exists at daily to monthly timescales. The vertical shear occurs throughout depth for the alongshore component while for the across-shore flow it occurs between 5 and $10 \mathrm{~m}$ below the surface. The mean across-shelf flow is offshore everywhere with largest values exceeding $3 \mathrm{~cm}$ $\mathrm{s}^{-1}$ above 7-m depth at the two offshore moorings (Figure 10b). For comparison Fig. 10c shows the vertical density stratification at C3 from 16 CTD casts taken at this location during three 6-day cruises. Most of the across-shore flow takes place in the 10-m-thick surface layer above the pycnocline. The across-shore flow pattern indicates a large divergence between $\mathrm{C} 1$ and $\mathrm{C} 2$ that appears qualitatively consistent with $2 \mathrm{D}$ surface Ekman dynamics; however, in actual fact it is not since the onshore bottom flux does not balance the offshore surface flux. The large offshore flow suggests that alongshore convergence must occur at monthly timescales. Note also that the depth-averaged across-shelf flow does not vanish anywhere, even though it becomes small about $7 \mathrm{~km}$ from the coast (Fig. 10b). The flow field is thus strongly three-dimensional at monthly timescales.

We remove the monthly flow of Fig. 10 from both the analyses of principal components and CEOFs that follow. We will thus describe statistical flow field properties from daily to monthly scales. Figure 11 depicts the properties of the principal components that describe the vertical variations of the current ellipse for a single mooring deployed at the 19-m isobath (C2, see Fig. 1 for location). Figure 11 shows ellipse parameters as a function of depth. The amplitude of the major (minor) axis diminishes from $14 \mathrm{~cm} \mathrm{~s}^{-1}\left(5 \mathrm{~cm} \mathrm{~s}^{-1}\right)$ near the surface to $4 \mathrm{~cm} \mathrm{~s}^{-1}\left(2 \mathrm{~cm} \mathrm{~s}^{-1}\right)$ at depth. The current ellipses thus become more circular with depth. Most remarkable, however, is the distinct veering of the semimajor axis from about $25^{\circ}$ at $5-\mathrm{m}$ depth to $70^{\circ}$ almost $18 \mathrm{~m}$ below the surface. This indicates the presence of a substantial across-shore velocity component if we define the alongshore direction as the orientation of the semimajor principal axis of the depth-averaged flow, which is about $43^{\circ}$. We will return to this point after inquiring if similar veering angles exist at other locations. For this purpose we depict the principal axes from all current meters as a hodograph in Fig. 12 that thus contains the information of Fig. 11 as a subset.

Figure 12 indicates that the amplitudes of the semimajor principal axis reach almost $10 \mathrm{~cm} \mathrm{~s}^{-1}$ at the surface and decreases to less than $4 \mathrm{~cm} \mathrm{~s}^{-1}$ at depth along the $25-\mathrm{m}$ isobath. Flows are somewhat stronger along the $10-\mathrm{m}$ isobath where near-surface currents reach 15 , 17 , and $19 \mathrm{~cm} \mathrm{~s}^{-1}$ from north to south at $\mathrm{N} 1, \mathrm{C} 1$, and $\mathrm{S} 1$, respectively. Along the northern $\mathrm{N}$ line both velocity components diminish toward the bottom concurrently. 

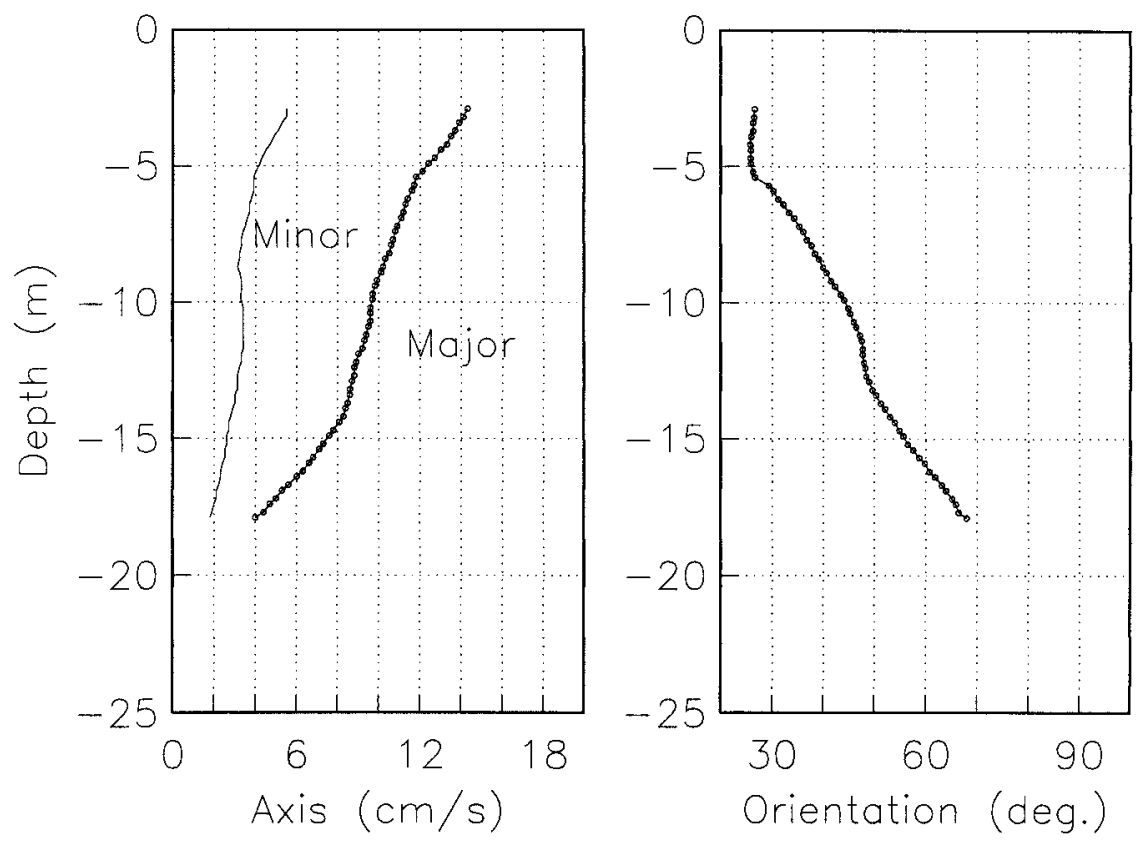

FIG. 11. Vertical distribution of principal axis properties at $\mathrm{C} 2$ on the $19-\mathrm{m}$ isobath.

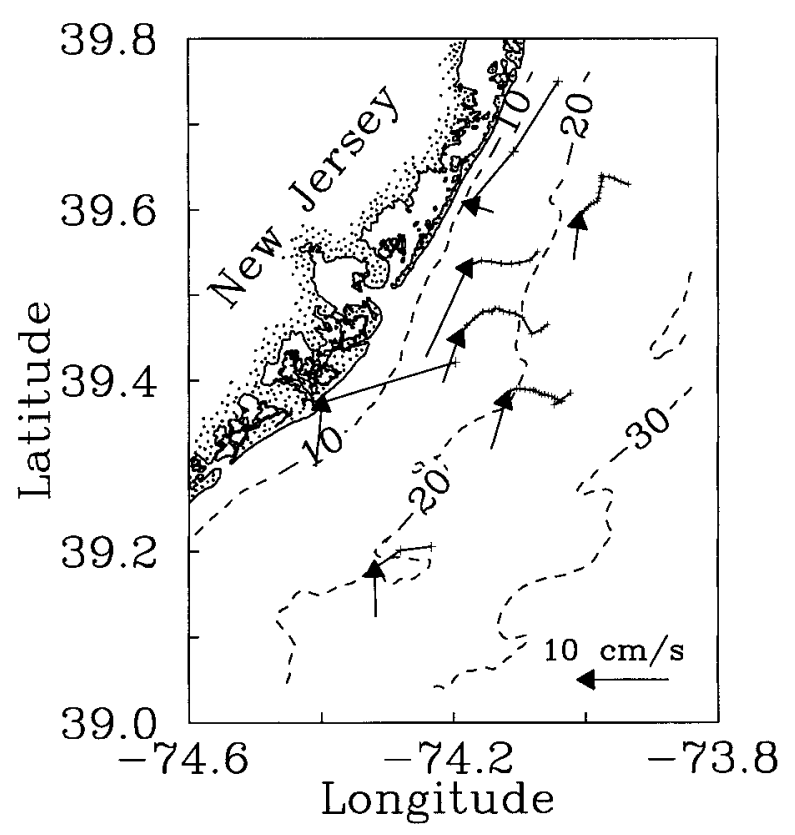

FIG. 12. Hodographs of the semimajor axis at all mooring locations. Each mooring location is indicated by the base of the arrow. The arrow head indicates the magnitude and orientation of the semimajor axis closest to the bottom. A line of symbols $(+)$ emanates from this point; each + symbolizes the head of arrow (not shown) that, if connected to the mooring location, represents the magnitude and orientation of a semimajor axis above the previous symbol. The symbols farthest to the east at the end of each line of symbols represents the semimajor axis closest to the surface. The veering of the major axes is thus always counterclockwise with increasing depth. The hodograph for N1 is offset $0.05^{\circ}$ long to the east for clarity (see Fig. 1 for exact location).
This contrasts with currents along the central C line and the southern $\mathrm{S}$ line where the across-shore component reduces sharply in magnitude toward the bottom while the alongshore component varies less with depth. Along the $\mathrm{C}$ line we discern a small clockwise veering (surface Ekman layer sense) that contrasts with large counterclockwise veering (bottom Ekman layer sense) at depths below. Axis orientations inshore change from about $30^{\circ}$ near the surface to almost $60^{\circ}$ near the bottom, while offshore they vary from the same surface value to more than $70^{\circ}$ near the bottom. These patterns foretell results of the CEOF analysis.

The first vertical CEOF mode at the offshore locations N3 (Fig. 13), C3, and S3 explain 80\%, 83\%, and 82\% of the total variance, respectively (Table 3 ). They exhibit similar characteristics as the principal components; that is, the veering is about $45-50$ degrees counterclockwise from the surface toward the bottom and the amplitudes vary from 2 to $4 \mathrm{~cm} \mathrm{~s}^{-1}$ just above the bottom to $10-$ $12 \mathrm{~cm} \mathrm{~s}^{-1} 5 \mathrm{~m}$ below the surface. At the inshore locations $\mathrm{N} 1, \mathrm{C} 1$, and $\mathrm{S} 1$ the patterns of the first mode are similar (not shown) with slightly reduced veering angles, somewhat increased amplitudes, and more variance explained. Both the first and the second CEOF modes at the central mooring $\mathrm{C} 2$ (not shown) appear similar in shape to the offshore moorings even though the time series cover a different time period. This gives confidence that the results are robust and well resolved in both time and space.

The second vertical CEOF modes reveal different patterns that are just as remarkable. Again the results resemble each other at most locations, and we thus discuss mode 2 only for N3, where it explains $15 \%$ of the total 

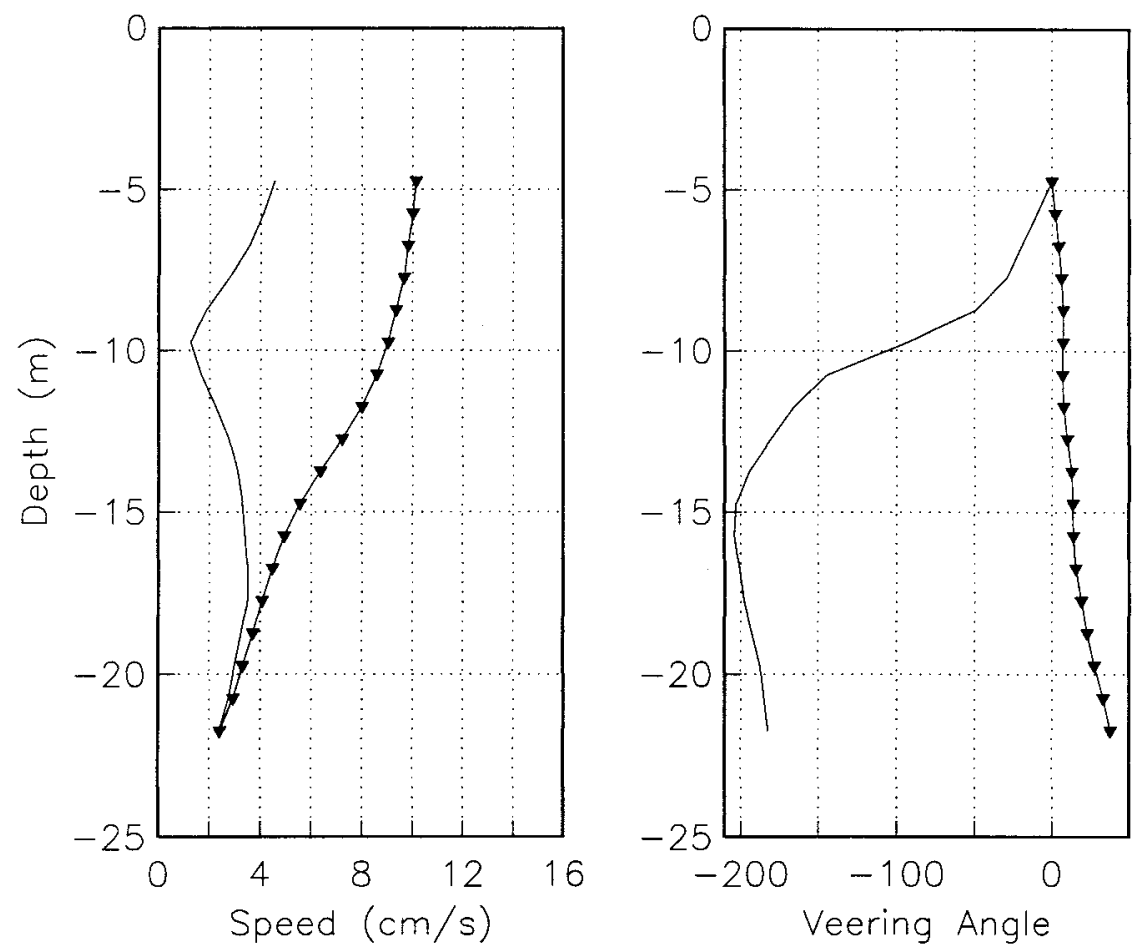

FIG. 13. Amplitude and veering angle for CEOF modes 1 (80\%, symbols) and 2 (15\%, line) for $\mathrm{N} 3$.

variance, respectively (Table 3). Amplitudes have a maximum at the surface of $4 \mathrm{~cm} \mathrm{~s}^{-1}$, reduce to a minimum of $2 \mathrm{~cm} \mathrm{~s}^{-1}$ at $10-\mathrm{m}$ depth, increase to a secondary maximum of almost $4 \mathrm{~cm} \mathrm{~s}^{-1} 18 \mathrm{~m}$ below the surface, and finally reduce uniformly toward the bottom (Fig. 13). The veering angle for this mode mimics the veering expected of distinct surface and bottom Ekman layers. Recall that all angles are counted positive counterclockwise. Near the surface the flow veers to the right with increasing depth to 15-m below the surface (clockwise, that is, angles become more negative with depth). Below this depth the sense of veering changes toward counterclockwise (in the sense of a bottom Ekman layer). The bottom veering reaches $50^{\circ}$ at N3 (counterclockwise, that is, angles become less negative with depth). Recall that the lower limit of the thermocline along the $25-\mathrm{m}$ isobath is about $18 \mathrm{~m}$ below the surface (Figs. 2 and 10c). The bottom veering thus occurs below the thermocline depth where temperatures are vertically uniform (Figs. 4 and 10c). It also coincides with the reduction of the amplitude toward the bottom.

Surface and bottom currents of the second CEOF mode are almost in opposite directions. It is tempting to associate the first mode with the alongshore currents and the second mode with the across-shore currents; however, this interpretation is problematic because large veering angles imply large across-shore velocities for both the first and the second mode. Instead, we interpret the first mode as wind- and buoyancy-forced motions that are both strongly affected by bottom friction and that are only weakly affected by vertical stratification. In contrast, we suspect that mode 2 is a frictional and baroclinic response to surface wind forcing. It apparently includes, qualitatively, the effects of surface and bottom Ekman layers. The subsurface minimum in speed $10 \mathrm{~m}$ below the surface occurs at the location of the upper thermocline (Fig. 4), and we thus speculate that interfacial friction may contribute to the dynamics (Garrett and Loder 1981) described statistically by this CEOF mode.

Table 4 lists the vector correlation for CEOF modes 1 and 2 at each location for both wind stress and pressure EOF. All correlations are significantly different from zero at $95 \%$ confidence using Eq. (2) to estimate degrees of freedom and the method first suggested by Sciremammano (1979) to estimate significance. The vector correlations between wind stress and mode- 1 currents are similar to those found in 1989 off Delaware about $100 \mathrm{~km}$ to the south (Münchow and Garvine 1993b). For comparison the vector correlations for the depthaveraged currents with the wind stress are also shown. They vary between $r=0.30$ at $\mathrm{N} 1$ and $r=0.54$ at S3. Maximum velocity correlations occur at 6-12 h lag for the wind stress at an angle counterclockwise from the wind that varies between $31^{\circ}$ at N3 and $60^{\circ}$ at N1. Currents measured offshore always correlate more strongly with the wind than do those measured inshore, while currents in the south correlate more strongly with the 
TABLE 4. Maximum correlation coefficients, angle of orientation, and lag time between time series of velocity and wind stress and between time series of velocity and pressure (EOF 1). The maximum correlation $r$ occurs at an angle $\alpha$ at a lag $\Delta t$. The angle $\alpha$ (positive counterclockwise) rotates the current vector into the orientation of the wind stress vector that results in maximum correlation. Negative lag indicates currents leading. All estimates are significant at the 95\% level of confidence according to the method suggested by Sciremammano (1979).

\begin{tabular}{|c|c|c|c|c|c|c|}
\hline & \multicolumn{2}{|c|}{ Depth-average } & \multicolumn{2}{|c|}{ CEOF 1} & \multicolumn{2}{|c|}{ CEOF 2} \\
\hline & Wind & Pressure & Wind & Pressure & Wind & Pressure \\
\hline \multicolumn{7}{|c|}{$r(-)$} \\
\hline $\mathrm{N} 1$ & 0.30 & 0.52 & 0.33 & 0.53 & 0.34 & 0.39 \\
\hline N3 & 0.41 & 0.66 & 0.42 & 0.63 & 0.29 & 0.40 \\
\hline $\mathrm{C} 1$ & 0.43 & 0.56 & 0.43 & 0.57 & 0.23 & 0.28 \\
\hline $\mathrm{C} 3$ & 0.47 & 0.68 & 0.48 & 0.68 & 0.28 & 0.36 \\
\hline $\mathrm{S} 1$ & 0.37 & 0.62 & 0.34 & 0.61 & 0.44 & 0.35 \\
\hline S3 & 0.54 & 0.67 & 0.55 & 0.63 & 0.24 & 0.33 \\
\hline \multicolumn{7}{|c|}{ Angle $\alpha(\operatorname{deg})$} \\
\hline $\mathrm{N} 1$ & -60 & $\mathrm{n} / \mathrm{a}$ & -78 & $\mathrm{n} / \mathrm{a}$ & 90 & $\mathrm{n} / \mathrm{a}$ \\
\hline N3 & -31 & $\mathrm{n} / \mathrm{a}$ & -55 & $\mathrm{n} / \mathrm{a}$ & 80 & $\mathrm{n} / \mathrm{a}$ \\
\hline $\mathrm{C} 1$ & -38 & $\mathrm{n} / \mathrm{a}$ & -95 & $\mathrm{n} / \mathrm{a}$ & -174 & $\mathrm{n} / \mathrm{a}$ \\
\hline C3 & -40 & $\mathrm{n} / \mathrm{a}$ & -87 & $\mathrm{n} / \mathrm{a}$ & -127 & $\mathrm{n} / \mathrm{a}$ \\
\hline $\mathrm{S} 1$ & -37 & $\mathrm{n} / \mathrm{a}$ & -79 & $\mathrm{n} / \mathrm{a}$ & -91 & $\mathrm{n} / \mathrm{a}$ \\
\hline S3 & -55 & $\mathrm{n} / \mathrm{a}$ & -82 & $\mathrm{n} / \mathrm{a}$ & -156 & $\mathrm{n} / \mathrm{a}$ \\
\hline \multicolumn{7}{|c|}{ Lag $\Delta \mathrm{t}$ (days) } \\
\hline N1 & 0.25 & -1.75 & 0.50 & -1.50 & -6.50 & -0.75 \\
\hline N3 & 0.25 & -1.00 & 0.25 & -1.00 & 9.00 & -6.00 \\
\hline $\mathrm{C} 1$ & 0.25 & -1.00 & 0.25 & -1.00 & -7.50 & -0.75 \\
\hline C3 & 0.25 & -1.00 & 0.25 & -1.00 & 9.00 & 7.50 \\
\hline $\mathrm{S} 1$ & 0.25 & -1.25 & 0.50 & -1.25 & 0.50 & -10.00 \\
\hline S3 & 0.25 & -1.25 & 0.25 & -1.25 & 3.75 & -9.50 \\
\hline
\end{tabular}

wind than do currents in the north. These findings are internally consistent with the hypothesis that the dynamics inshore and in the north are more frequently affected by the buoyant Hudson coastal current than those in the south and offshore. The velocity correlations with the first EOF of the pressure field (Figs. 8c and 9) are numerically larger; however, they are less significant than the wind correlations. The longer timescale of the pressure fluctuation (not shown) and the efficient removal of noise by the EOF analysis decreases the effective degrees of freedom in the correlation analysis. Nevertheless, currents always lead pressure fluctuations by about a day.

We now expand our view from a one-dimensional vertical perspective to a two-dimensional across-shore perspective. Figure 14 depicts the CEOF amplitudes and veering angles of our central across-shelf section. The statistically significant modes 1 and 2 , respectively, explain $71.5 \%$ and $14.8 \%$ of the variance of 44 current time series at $\mathrm{C} 1, \mathrm{C} 2$, and $\mathrm{C} 3$. Mode 1 depicts a broad surface-intensified jet centered at $\mathrm{C} 2$ with large vertical shears inshore but not offshore (Fig. 14a). The veering to the left with depth is almost uniform across the inner shelf. In contrast, the spatial pattern of mode 2 represents inshore and offshore motions that are almost in opposite directions with very little vertical veering (Fig. $14 \mathrm{~b})$. It thus resembles mode 2 of the depth-averaged flow field (Fig. 6d). Most of the horizontal change of direction takes place between $\mathrm{C} 2$ and $\mathrm{C} 3$. We speculate that it reflects different current regimes separated by frontal features such as those shown in Fig. 2. More extensive survey work (not discussed here) indicates that density fronts occur frequently between these two locations during both wind-forced upwelling (lighter waters offshore) and buoyancy-forced downwelling (lighter waters inshore) events. Additionally, the opposing flows inshore and offshore expressed statistically by this mode describe conditions during periods of wind relaxation (CM98).

The spatial patterns discussed above are temporally modulated in both intensity and orientation. Figure 15 shows vectors $A_{n}(t)$ that represent temporal modulations of the spatial patterns for modes 1 and 2. Each time series is scaled such that the total variance of the time series is 1 . The ratio of the semiminor to the semimajor axes are 0.21 and 0.41 for modes 1 and 2, respectively. The higher modes become increasingly more circular. We also note that Fig. 15 closely resembles the temporal CEOF amplitudes of the depth-averaged currents shown in Fig. 8. This similarity constitutes both a surprising and important result since the two analyses describe different locations, time periods, and, presumably, dynamics. The strong similarity thus provides additional evidence on the rebustness of our results.

The time series of mode 1 suggests five different "events," which we label U1, U3, R1, B1, and B2 for upwelling (U), relaxation (R), and buoyancy (B): $A_{1}(t)$ is strongly positive from day $158-165$ (U1) and 192202 (U3) during strong upwelling favorable winds, it is close to zero during day 202-210 (R1) during a relaxation period (CM98), and it is strongly negative from day 168-172 (B1) and 200-220 (B2a and B2b) when 
A Amplitude $(\mathrm{cm} / \mathrm{s})$

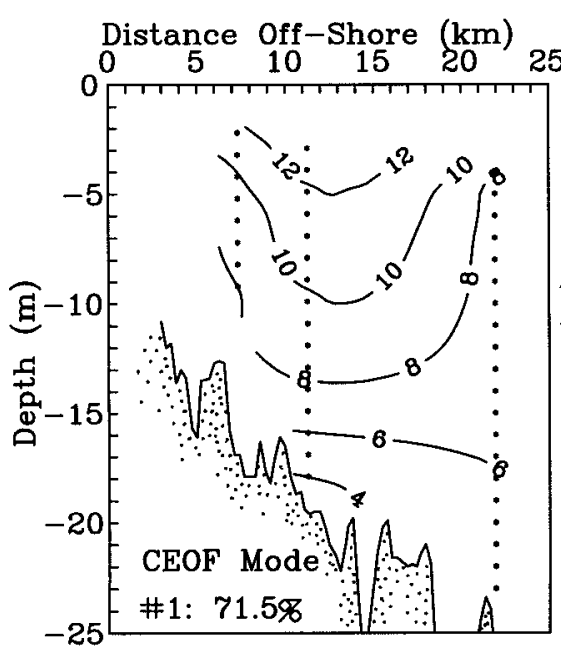

Veering (Deg.)

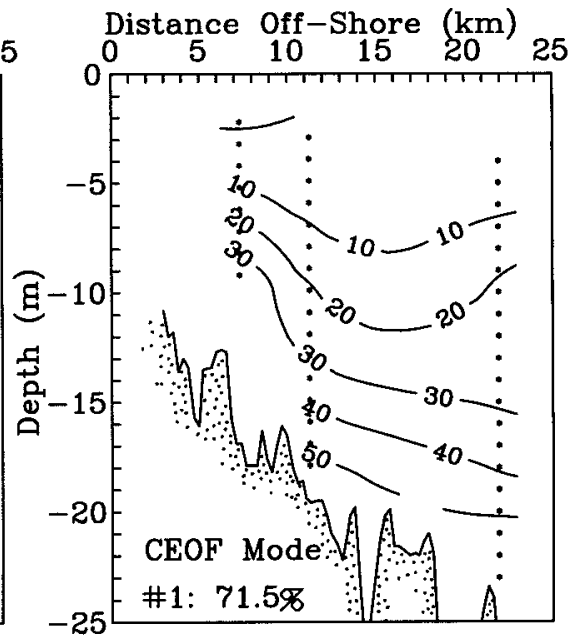

Veering (Deg.)

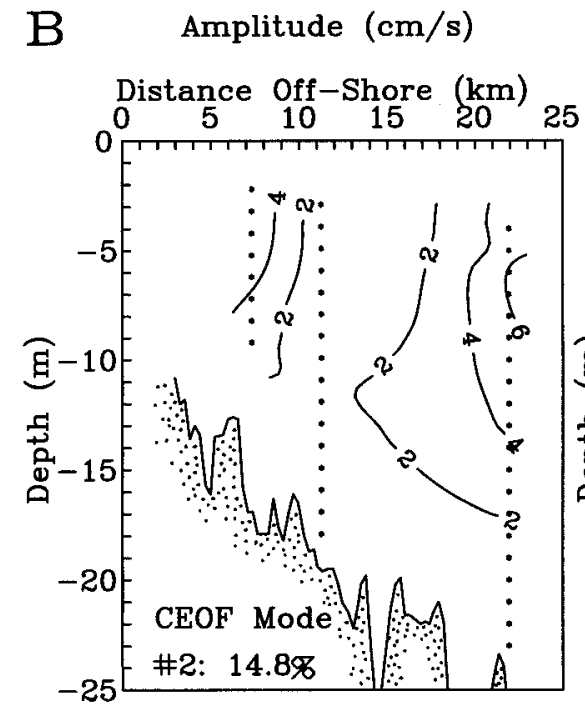

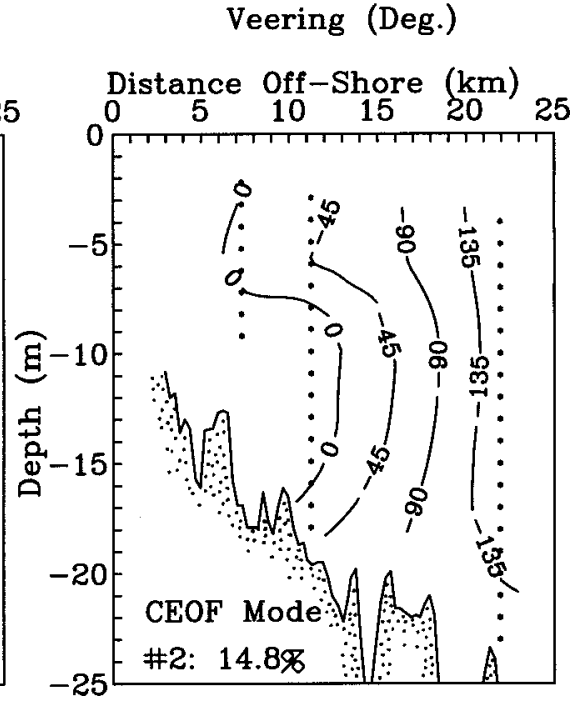

FIG. 14. Amplitude and veering angle for CEOF modes (a) 1 and (b) 2 along the central C line. Left panels indicate the amplitude (in $\mathrm{cm} \mathrm{s}^{-1}$ ) while the right panels indicate the veering angles (positive angles increase counterclockwise).

buoyant waters passed through our study area (Yankovsky and Garvine 1998; Yankovsky et al. 2000). The time series of mode 2 indicates four events lasting longer than 5 days. The amplitude $A_{2}(t)$ is strongly negative from day 158 to 165 (U1) and day 212 to 220 (U3 and B2a) while it is positive from day 168 to 172 and 200 to $212(\mathrm{~B} 2 \mathrm{~b})$. At all other times $A_{2}(t)$ represents highfrequency motion since it changes sign almost daily while its amplitude is generally small.

To classify and physically interpret the CEOF modes we discuss tendencies of modal patterns. We hope to concisely describe a limited number of generally observable scenarios that distinctly characterize different spatial aspects of the flow field. The concept is common in synoptic meteorology as forecasters subjectively classify events by a limited number of empirical patterns and scenarios. Harms and Winant (1998) introduced this approach to coastal physical oceanography. We will test our interpretations by selecting four maps (of 1034 available) of observed surface currents from OSCR measurements using the "tendencies" of temporal CEOF amplitudes as the only selection guide.

We define a tendency by the sign of the temporal amplitude $A_{n}(t)$ during a period when the sign is uniform. A tendency can be positive $(+)$, negative $(-)$, or weak and variable $(O)$. Table 5 lists tendencies during the events marked in Fig. 16 for modes 1, 2, and 3. The mode-1 tendencies suggest that upwelling events are 


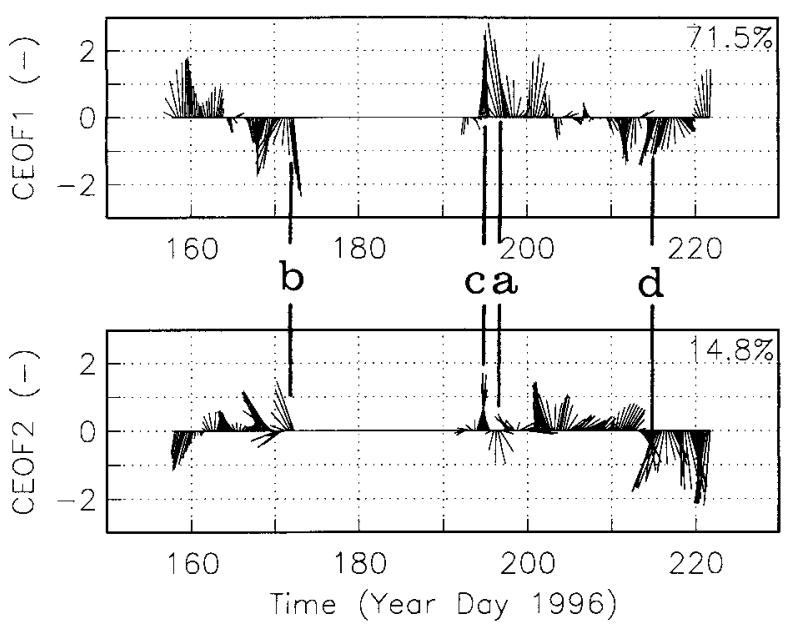

FIG. 15. Temporal amplitudes associated with the CEOF along the C line. There are no data between day 172 and day 192. Labels for events (a) upwelling inshore (day 196), (b) buoyancy inshore (day 172), (c) upwelling offshore (day 193), and (d) buoyancy offshore (day 214) refer to events shown in Fig. 16.

characterized by the positive phase while buoyancy events are characterized by its negative phase. Relaxation, meandering, and eddy development characterize the flow field at times when mode 1 is weak and mode 2 dominates. CM98 describe such an event and its dynamics in detail and we thus refrain from a discussion here. The tendencies of mode 2 add (subtract) to the tendencies of mode 1 if both tendencies carry the same (opposite) sign. We thus expect two "flavors" of both buoyancy and upwelling events depending on the respective signs of mode 1 and 2 .

Subtracting the spatial patterns of modes 1 and 2 (Fig. 14), we find a coastal jet that diminishes in speed offshore (not shown). Vertical shears are large inshore while horizontal shears are large everywhere except at depths below $15 \mathrm{~m}$. We label these tendencies "upwelling inshore" and "buoyancy inshore" if $A_{1}(t)$ is positive and negative, respectively, and if the sign of $A_{2}(t)$ opposes the sign of $A_{1}(t)$. Figures $16 \mathrm{a}$ and $16 \mathrm{~b}$ depict detided, hourly averaged surface flow fields from OSCR for the "upwelling inshore" and "buoyancy inshore" tendencies. These synoptic events represent the early stages of wind-forced upwelling $\left(A_{1}>0\right.$; Fig. 16a) and buoyancy-forced downwelling $\left(A_{1}<0\right.$, Fig. 16b) circulation. Over time these inshore features migrate offshore either, we speculate, as the result of sustained upwelling favorable winds that advect the density field offshore or as the result of current instability. Such offshore patterns result if we add the spatial patterns of modes 1 and 2 . It then represents a broad, vertically sheared flow with largest velocities offshore (not shown). The inshore flow is both weak and vertically uniform. Figures $16 \mathrm{c}$ and $16 \mathrm{~d}$ depict realizations of these two scenarios that we term "upwelling offshore" $\left[A_{1}(t)\right.$ $>0]$ and "buoyancy offshore" $\left[A_{1}(t)<0\right]$ events. The time of the OSCR fields was chosen to correspond to the time when the tendencies of modes 1 and 2 carry the same sign. Subsequent work will need to verify, describe, and most importantly, dynamically analyze the proposed scenarios in detail.

\section{Summary and conclusions}

We analyzed observations of the temperature, pressure, and velocity fields off New Jersey during the 1996 summer stratified season. Even though the water is less than $30 \mathrm{~m}$ deep $20 \mathrm{~km}$ from the coast, we found vertically and horizontally strongly stratified waters most of the time. Record mean temperatures varied vertically by more than $5^{\circ} \mathrm{C}$ and $10^{\circ} \mathrm{C}$ inshore and offshore, respectively. Salinity differences, too, contributed to the density field as waters fresher than 28 psu passed our mooring array intermittently both inshore and offshore. The most likely source of such freshwater is the Hudson River about $100 \mathrm{~km}$ to the north. The moderate winds were generally upwelling favorable and we observed several upwelling events when surface and/or bottom temperatures dropped by almost $6^{\circ} \mathrm{C}$ following days 153, 181, 197, and 213.

Low-passed filtered currents exceeded $30 \mathrm{~cm} \mathrm{~s}^{-1}$ inshore while offshore they rarely reached $10 \mathrm{~cm} \mathrm{~s}^{-1}$. Record mean currents were generally weak $\left(<5 \mathrm{~cm} \mathrm{~s}^{-1}\right)$, but revealed an intriguing pattern. The alongshore surface flow was in the direction of the upwelling favorable winds, but reduced to zero inshore. In contrast, a bottom flow opposes the local winds, is largest inshore, and

TABLE 5. Tendencies of temporal modal amplitudes $A_{1}(t), A_{2}(t)$, and $A_{3}(t)$ during distinct events. Examples of the events indicated in bold type are shown in Fig. 17.

\begin{tabular}{|c|c|c|c|c|c|c|}
\hline Event & Time & $A_{1}$ & $A_{2}$ & $A_{3}$ & Type & Evidence \\
\hline $\mathrm{U} 1$ & $158-165$ & + & - & o & Upwelling inshore & Survey 1: $162-167$ \\
\hline B1 & $168-172$ & - & + & o & Buoyancy inshore & $\begin{array}{l}\text { Survey 2: } 180-185 \\
\text { Yankovsky and Garvine (1998) }\end{array}$ \\
\hline U3a & 193-195 & + & + & - & Upwelling offshore & \\
\hline U3b & $195-200$ & + & - & o & Upwelling inshore & \\
\hline $\mathrm{U} 3 \mathrm{c}$ & $200-202$ & + & + & + & Upwelling offshore & \\
\hline R1 & $202-210$ & o & + & o & Relaxation & Chant and Münchow (1998) \\
\hline B2a & $210-212$ & - & + & o & Buoyancy inshore & \\
\hline B2b & $212-220$ & - & - & o & Buoyancy offshore & $\begin{array}{l}\text { Survey 3: } 213-218 \\
\text { Yankovsky et al. (2000) }\end{array}$ \\
\hline
\end{tabular}



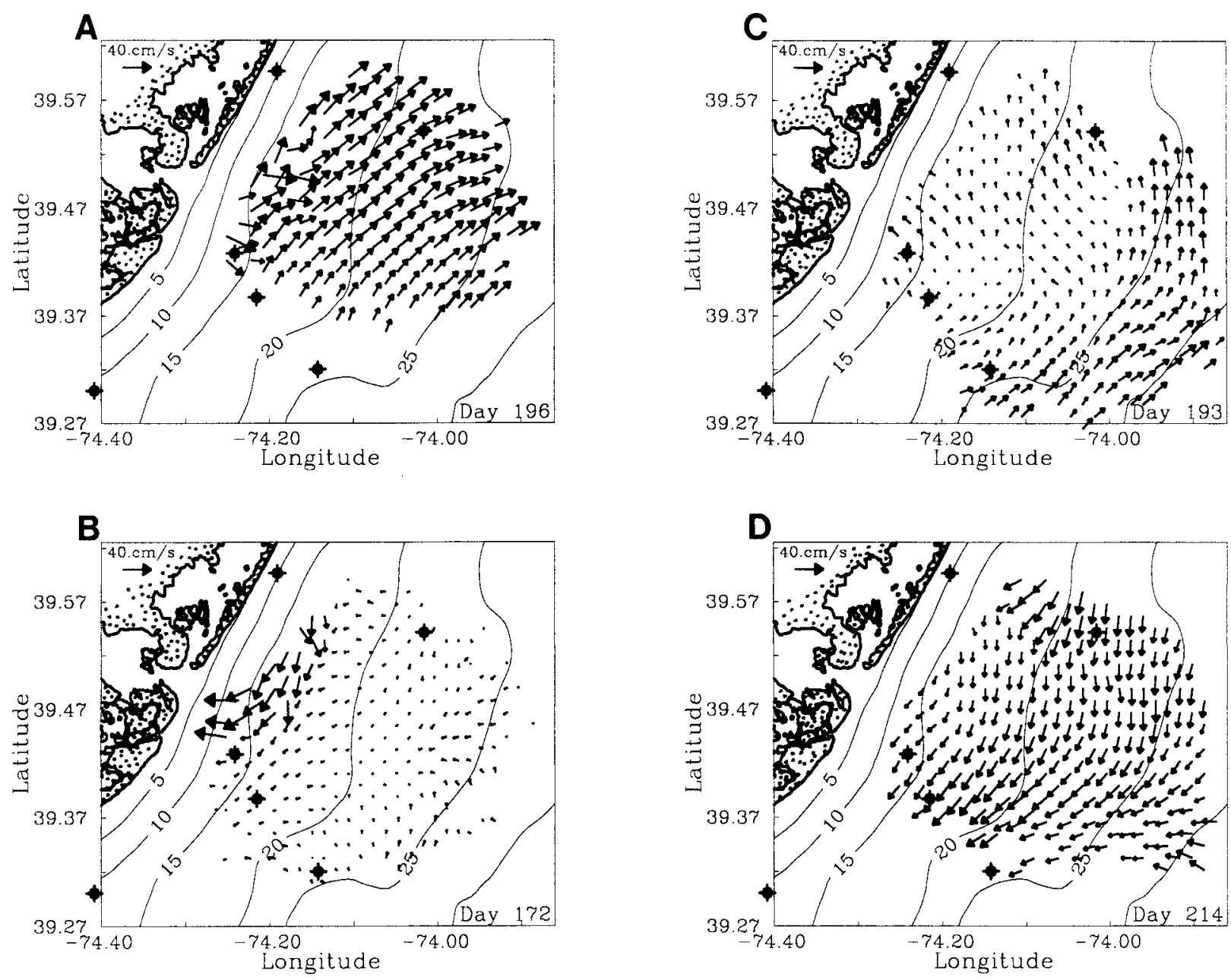

FIG. 16. Maps of hourly averaged, detided OSCR maps to represent flow realizations suggested by the tendencies of CEOF modes 1 and 2 for currents across the C-line: (a) upwelling inshore, day 196; (b) buoyancy inshore, day 172; (c) upwelling offshore, day 193; and (d) buoyancy offshore, day 214 .

diminishes offshore. We also found a mean across-shore flow in excess of $3 \mathrm{~cm} \mathrm{~s}^{-1}$ offshore at the surface without a compensating onshore flow at depth. The flow field is thus strongly three-dimensional. The pressure field supports this finding as its first EOF mode suggests both across- and alongshore pressure gradients. This mode explains more than $94 \%$ of the total subtidal variance. Upwelling favorable winds coincide with across-shore pressure gradients, indicative of a barotropic geostrophic flow component, while a concurrent alongshore pressure gradient opposes the wind stress. We speculate that the upwelling favorable winds cause a local setup of sea level off Long Island, which blocks the northward alongshelf flow (see Fig. 1 for location).

We also found an unexpected amount of current veering with depth in the bottom Ekman layer sense at all timescales. This veering, about $30^{\circ}-70^{\circ}$ counterclockwise with depth, is generally continuous with depth at a rate of about $2-3 \mathrm{deg} / \mathrm{m}$. Both $\mathrm{ADCP}$ and $\mathrm{S} 4$ current meter moorings show this veering with depth. It occurs during wind-forced upwelling events and it occurs during buoyancy-forced downwelling events. It occurs inshore where the vertical stratification is weak and offshore where the vertical stratification is strong. It emerges as the major feature from both principal component analysis and it emerges as a major feature from $\mathrm{CEOF}$ analyses. The veering is contained within the first CEOF mode that explains more than $72 \%$ of the variance of 44 current time series from a single across-shelf section. We thus conclude that the counterclockwise veering with increased depth is a robust feature.

Our results largely contrast with observations elsewhere such as those made during the 1981/82 CODE experiment off California. There the shelf is much deeper $(\sim 100 \mathrm{~m})$, narrower $(\sim 25 \mathrm{~km})$, and more steeply sloping $\left(4 \times 10^{-3}\right)$. An extensive moored array was deployed generally seaward of the $60-\mathrm{m}$ isobath about $3 \mathrm{~km}$ from the coast. Lentz (1994) describes EOFs from the shallowest CODE mooring with five current meters that was deployed in water about $30 \mathrm{~m}$ deep. His first 
EOF explains $89 \%$ of the total variance and currents also veer counterclockwise with depth; however, they do so by less than $15^{\circ}$. Smith (1981) presents EOF modes of vertical currents observed off Oregon, northwest Africa, and Peru where the first mode of 11, 6, and 12 instruments explains $72 \%, 75 \%$, and $76 \%$ of the total variance, respectively. This is similar to what we observe; that is, our first CEOF explains $80 \%$ (N3), 86\% (C3), and $91 \%$ (C2) of the total variance: However, in contrast to our results off New Jersey, the first EOFs off Oregon, northwest Africa, and Peru veer only $20^{\circ}$, $30^{\circ}$, and $8^{\circ}$ over the top $80 \mathrm{~m}$ of a much deeper water column.

The observed large counterclockwise veering and the smooth, almost linear reduction of amplitude with depth is incompatible with coastal Ekman dynamics. If the water depth $D$ is of the same order of magnitude as the Ekman-layer depth $\delta_{\mathrm{E}}$, that is, $E_{v}=\left(\delta_{E} / D\right)^{2} \sim O(1)$, then the surface-to-bottom veering angle is close to zero, as rotation becomes negligible irrespective of the vertical eddy viscosity profile used (Lentz 1995a). For deep water with $E_{v} \ll 1$, the theory predicts a surface-tobottom counterclockwise veering angle of the order of magnitude that we observe off New Jersey; however, most of this veering is concentrated within distinct surface and bottom layers. This we do not observe. Instead of distinct surface or bottom boundary layers, we find generally uniform veering at a rate of about $2-3 \mathrm{deg} / \mathrm{m}$. While we cannot yet explain the large veering of current fluctuations, we do hypothesize that a fluctuating alongshore density gradient contributes to the vertical veering through the thermal wind relation. If the seasonal pycnocline in the Mid-Atlantic Bight slopes by about $5 \mathrm{~m}$ in $50 \mathrm{~km}$ along the shore, it would add roughly $3 \mathrm{~cm}$ $\mathrm{s}^{-1}$ vertical shear in the across-shore velocity component. This shear would enhance the vertical veering if it slopes downward to the north during downwelling/ buoyancy events and the reverse during upwelling events. The testing of this hypothesis will require highresolution repeat surveys of the three-dimensional density fields in our study area. Such work is in progress.

In contrast to locations off Oregon, northwest Africa, Peru, and California, currents on the inner shelf off New Jersey reverse their direction frequently as the result of both relaxing winds and the advection of buoyant waters of the Hudson coastal current. The local wind forcing in our study area is both weaker and less persistent than it is in the eastern boundary current regimes during the upwelling season. The timescales of the subtidal flow field thus are much smaller and the flow is often unsteady. The veering, however, persists during upwelling, downwelling, and buoyancy forced events. It is an intrinsic feature of the flow field on the inner shelf in the summer.

Acknowledgments. The experiment was a joint effort with Richard Garvine of the University of Delaware (UD) and Scott Glenn of Rutgers University (RU). The
ADCP and pressure sensor mooring work was accomplished through the successful cooperation of a group of divers from both universities. The S4 current meters were deployed from the R/V Cape Henlopen under the competent and cheerful leadership of Captain Matt Hawkins and Tim Pfeiffer (UD). David Huntley and Hank Statscewich (RU) were instrumental in the many details of the field work, data processing, and the preparation of graphics. We thank Sasha Yankovsky (UD) and Laurel Henderson (RU) for the initial processing of the S4 current meter and pressure sensor data. Hans Graber of University of Miami provided the OSCR unit and his group provided crucial assistance during its difficult operation in the field. Eddy Carmack of the Canadian Institute of Ocean Sciences in Sidney, British Columbia, and Jim O'Donnell of the University of Connecticut generously and trustingly gave their ADCPs for the duration of this study. Comments by Scott Durski (RU), Jim Miller (RU), Sasha Yankovsky (UD), Richard Garvine (UD), and two anonymous reviewers greatly improved the manuscript. All data are accessible at http: //marine.rutgers.edu/ac/data.html. The National Science Foundation funded this study through Grant OCE-9528239.

\section{APPENDIX}

\section{Empirical Orthogonal Functions}

An empirical orthogonal function decomposes observations $U\left(x_{i}, t\right)$ at location $x_{i}$ and time $t$ according to

$$
U\left(x_{i}, t\right)=\sum_{n} A_{n}(t) \cdot \phi_{n}\left(x_{i}\right),
$$

where the index $n$ represents a mode of variability and $A_{n}(t)$ and $\phi_{n}\left(x_{i}\right)$ represent temporal amplitudes and spatial pattern, respectively, for the $n$th mode. Formally, $A_{n}(t)$ and $\phi_{n}\left(x_{i}\right)$ are eigenfunctions and eigenvectors, respectively, to the eigenvalue problem

$$
\mathbf{R}_{i j} \phi_{i}=\lambda_{i} \phi_{i},
$$

where $\mathbf{R}_{i j}$ constitutes the zero lag cross-covariance matrix of observations at locations $x_{i}$ and $x_{j}$ and $\lambda_{i}$ is the eigenvalue for the $i$ th mode. Our analyses thus address in-phase or standing pattern only. This is distinct from more sophisticated so-called "extended" (Weare and Nasstrom 1982), "complex" (Horel 1984), and frequency-domain (Wallace and Dickinson 1972) EOF analyses that all attempt to detect propogating patterns. Each mode is orthogonal; that is, $\phi_{i} \cdot \phi_{j}=\delta_{i j}$ where $\delta_{i j}$ represents the Kronecker delta $\left(\delta_{i j}=1\right.$ for $i=j$ while $\delta_{i j}=0$ for $\left.i \neq j\right)$. The eigenvalues $\lambda_{i}$ indicate the amount of the total variance that is explained by the mode. The decomposition is purely statistical and does not necessarily bear on the dynamics or physical structure of the observed fields. Davis (1976) and Kundu and Allen (1976) introduced the method to oceanography; however, Richman (1986) discusses their drawbacks and 


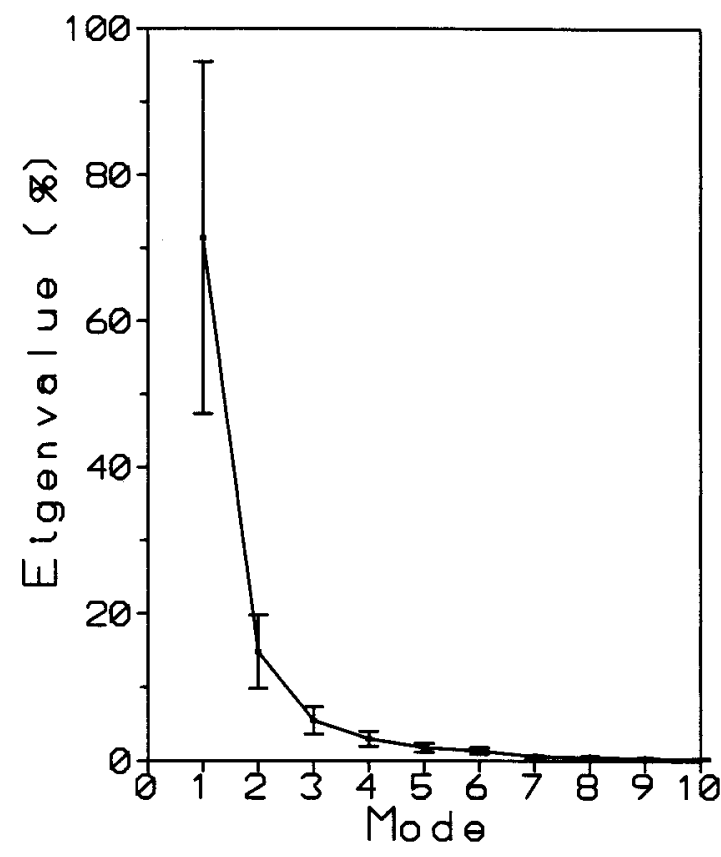

FIG. A1. Eigenvalues and their uncertainties as a function of mode number for the CEOF analysis along the $\mathrm{C}$ line (Figs. 15 and 16). Note that only the first and second eigenvalue are distinct while all others overlap.

limitations. North et al. (1982) and Overland and Preisendorfer (1982) derived error estimation procedures and mode selection rules. Uncertainties due to measurement errors will result in uncertainties $\delta\left(\lambda_{i}\right)$ for the eigenvalue $\lambda_{i}$. If eigenvalues overlap, then their pattern will not be truly orthogonal. A first estimate of $\delta\left(\lambda_{i}\right)$ is

$$
\delta\left(\lambda_{i}\right)=\lambda_{i}(2 / N)^{1 / 2},
$$

where $N$ represents the degrees of freedom of the dataset that we determine according to Eq. (2) with $C_{x x}(t)$ and $C_{y y}(t)$ representing the lagged autocorrelation functions of the east and north components of the velocity vector, respectively. The decorrelation timescales $T_{D}$ are listed in Table 3. If we choose for the $\mathrm{C}$ line a conservative value of $T_{D}=2$ days, then the CEOF analysis of 44 time series each 44 days long (Figs. 16 and 17) has $N$ $=22$ degrees of freedom. Figure A1 shows the eigenvalues $\lambda_{i}$ and their uncertainty $\delta\left(\lambda_{i}\right)$ for this example. The first and second modes are distinct; however, the third mode is not since its error bars overlap with those of mode 4 .

\section{REFERENCES}

Allen, J. S., P. A. Newberger, and J. Federiuk, 1995: Upwelling circulation on the Oregon continental shelf. Part I: Response to idealized forcing. J. Phys. Oceanogr., 25, 1843-1866.

Blanton, J. O., 1975: Nearshore lake currents measured during upwelling and downwelling of the thermocline in Lake Ontario. $J$. Phys. Oceanogr., 5, 111-124.

Brink, K. H., and T. J. Cowles, 1991: The coastal transition zone program. J. Geophys. Res., 96, 14 637-14 647.
, D. C. Chapman, and G. Halliwell Jr., 1987: A stochastic model for wind-driven currents over the continental shelf. J. Geophys. Res., 92, 1783-1797.

Chapman, D. C., and S. J. Lentz, 1994: Trapping of a coastal density front by the bottom boundary layer. J. Phys. Oceanogr., 24, $1464-1479$.

Chereskin, T. K., 1995: Direct evidence for an Ekman balance in the California Current. J. Geophys. Res., 100, 18 261-18 269.

Collins, C. A., C. N. K. Mooers, M. R. Stevenson, R. L. Smith, and J. G. Patullo, 1968: Direct current measurements in the frontal zone of a coastal upwelling region. J. Oceanogr. Soc. Japan, 24, 295-306.

Csanady, G. T., 1972: The coastal boundary layer in Lake Ontario. J. Phys. Oceanogr., 2, 168-176.

_ 1978: The arrested topographic wave. J. Phys. Oceanogr., 8, 47-62.

— 1997: On the theories that underlie our understanding of continental shelf circulation. J. Oceanogr. Soc. Japan, 53, 207-229.

Davis, R. E., 1976: Predictability of sea surface temperature and sea level pressure anomalies over the North Pacific Ocean. J. Phys. Oceanogr., 6, 249-266.

Ekman, V. W., 1905: On the influence of the earth's rotation on ocean currents. Ark. Mat. Astron. Fys., 2, 1-53.

_ 1906: Ströme und Stromsysteme, die vom Winde unter dem Einfluss der Kontinente verursacht werden. Annalen der Hydrographie und Maritimen Meteorologie, 527-540.

Federiuk, J., and J. S. Allen, 1995: Upwelling circulation on the Oregon continental shelf. Part II: Simulations and comparisons with observations. J. Phys. Oceanogr., 25, 1867-1889.

Fofonoff, N. P., and H. L. Bryden, 1975: Density of sea water. $J$. Mar. Res., 41, 69-82.

Garrett, C. J. R., and J. W. Loder, 1981: Dynamical aspects of shallow sea fronts. Philos. Trans. Roy. Soc. London, A320, 563-581.

Glenn, S. M., M. F. Crowley, D. B. Haidvogel, and Y. T. Song, 1996: Underwater observatory captures coastal upwelling events off New Jersey. Eos, Trans. Amer. Geophys. Union, 77 (25), 233.

Harms, S., and C. D. Winant, 1998: Characteristic patterns of circulation in the Santa Barbara Channel. J. Geophys. Res., 103, 3041-3065.

Horel, J. D., 1984: Complex principal component analysis: Theory and examples. J. Climate Appl. Meteor., 23, 1660-1673.

Houghton, R. W., R. Schlitz, R. C. Beardsley, B. Butman, and J. Lockwood Chamberlin, 1982: The Middle Atlantic Bight cold pool: Evolution of the temperature structure during the summer of 1979. J. Phys. Oceanogr., 12, 1019-1029.

Kundu, P. K., and J. S. Allen, 1976: Some three-dimensional characteristics of low-frequency current fluctuations near the Oregon coast. J. Phys. Oceanogr., 6, 181-199.

Lentz, S. L., 1992: The surface boundary layer in coastal upwelling regions. J. Phys. Oceanogr., 22, 1517-1539.

- 1994: Current dynamics over the Northern California inner shelf. J. Phys. Oceanogr., 24, 2461-2478.

_ 1995a: Sensitivity of the inner-shelf circulation to the form of the eddy viscosity profile. J. Phys. Oceanogr., 25, 19-28.

_ 1995b: U.S. contributions to the physical oceanography of continental shelves in the early 1990's. Rev. Geophys., 33 (Suppl.), $1225-1236$.

— the northern California shelf. J. Phys. Oceanogr., 21, 11861201.

McEwen, G. F., 1912: The distribution of ocean temperatures along the west coast of North America deduced from Ekman's theory of the upwelling of cold water from adjacent ocean depths. Internationale Revue der gesamten Hydrobiologie und Hydrographie.

Merrifield, M. A., and C. D. Winant, 1989: Shelf circulation in the Gulf of California: A description of the variability. J. Geophys. Res., 94, 18 133-18 160.

Münchow, A., 2000: Detiding three-dimensional velocity survey data in coastal waters. J. Atmos. Oceanic Technol., in press. 
— driven coastal current. J. Geophys. Res., 98, $20063-20078$.

$\longrightarrow$, and - 1993b: Buoyancy and wind forcing of a coastal current. J. Mar. Res., 51, 293-322.

- A. K. Masse, and R. W. Garvine, 1992: Astronomical and nonlinear tidal currents in a coupled estuary shelf system. Contin. Shelf Res., 12, 471-498.

North, G. R., T. L. Bell, R. F. Cahalan, and F. J. Moeng, 1982: Sampling errors in the estimation of empiricial orthogonal functions. Mon. Wea. Rev., 110, 699-706.

Overland, J. E., and R. W. Preisendorfer, 1982: A significance test for principal components applied to cyclone climatology. Mon. Wea. Rev., 110, 1-4.

Richman, M. B., 1986: Rotation of principal components. Int. J. Climatol., 6, 293-335.

Samelson, R. M., 1997: Coastal boundary conditions and the baroclinic structure of wind-driven continental shelf currents. J. Phys. Oceanogr., 27, 2645-2662.

Sciremammano, F., 1979: A suggestion for the presentation of correlations and their significance levels. J. Phys. Oceanogr., 9, 1273-1276.

Smith, R. L., 1981: A comparison of the structure and variability of the flow field in three coastal upwelling regions: Oregon, north- west Africa, and Peru. Coastal Upwelling, F. A. Richards, Ed., Amer. Geophys. Union, 107-118.

Sverdrup, H. U., 1938: On the process of upwelling. J. Mar. Res., 1, 155-164.

Thorade, H., 1909: Über die Kalifornischen Meeresströmungen an der Westküste Nordamerikas. Annalen der Hydrographie und Maritimen Meteorologie. Vol. 37.

Wallace, J. M., and R. E. Dickinson, 1972: Empirical orthogonal representation of time series in the frequency domain. Part I: Theoretical considerations. J. Appl. Meteor., 11, 887-892.

Weare, B. C., and J. S. Nasstrom, 1982: Eamples of extended empirical orthogonal function analysis. Mon. Wea. Rev., 110, 481485 .

Winant, C. D., R. C. Beardsley, and R. E. Davis, 1987: Moored wind, temperature, and current observations made during CODE-1 and CODE-2 over the northern California continental shelf and upper slope. J. Geophys. Res., 92, 1569-1604.

Yankovsky, A. E., and R. W. Garvine, 1998: Subinertial dynamics on the inner New Jersey shelf during the upwelling season. $J$. Phys. Oceanogr., 28, 2444-2458.

- - and A. Münchow, 2000: Mesoscale currents on the inner New Jersey shelf driven by the interaction of buoyancy and wind forcing. J. Phys. Oceanogr., in press. 